\title{
Suicidal behaviour
}

An epidemiological study of suicide and attempted suicide in relation to mental health services

By

Håkon A. Johannessen

Department of Suicide Research and Prevention, Division of Mental Health, Norwegian Institute of Public Health

Submitted for the degree of PhD at the Institute of Health and Society, Faculty of Medicine, University of Oslo 
(C) Håkon A. Johannessen, 2011

Series of dissertations submitted to the Faculty of Medicine, University of Oslo No. 1148

ISBN 978-82-8264-076-3

All rights reserved. No part of this publication may be reproduced or transmitted, in any form or by any means, without permission.

Cover: Inger Sandved Anfinsen.

Printed in Norway: AIT Oslo AS.

Produced in co-operation with Unipub.

The thesis is produced by Unipub merely in connection with the thesis defence. Kindly direct all inquiries regarding the thesis to the copyright holder or the unit which grants the doctorate. 



\section{Contents}

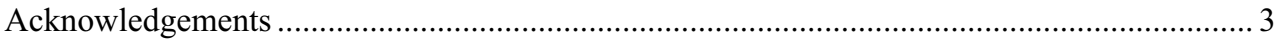

Summary

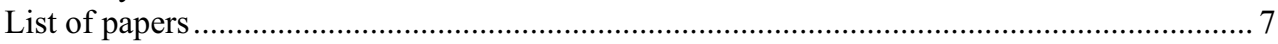

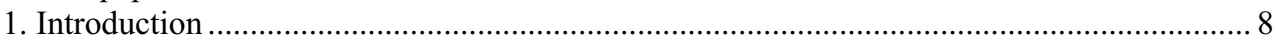

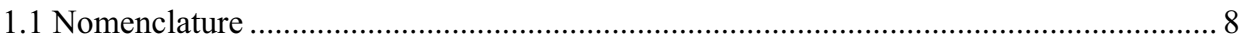

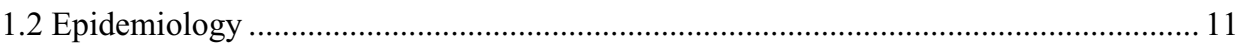

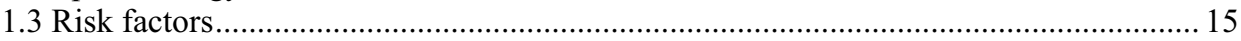

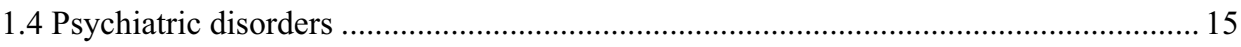

1.4.1 How much of the variation in suicide mortality is attributable to psychiatric

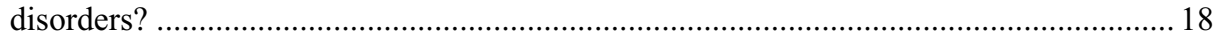

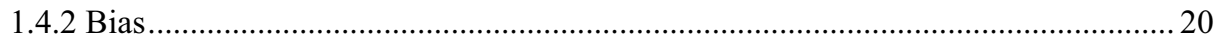

1.5 The relationship between mental health services and suicidal behaviour...................... 20

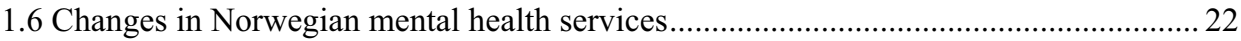

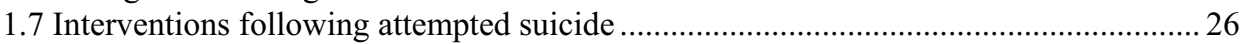

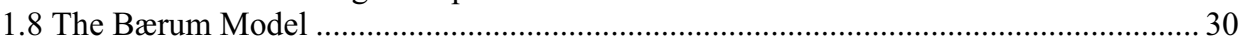

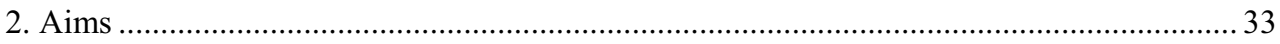

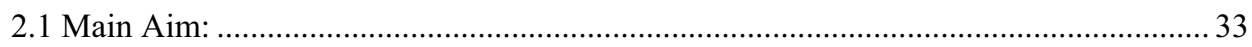

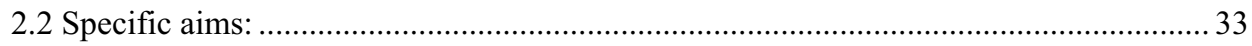

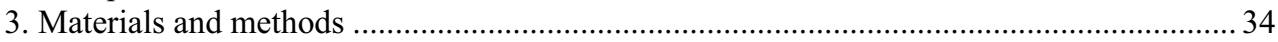

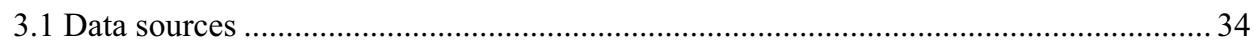

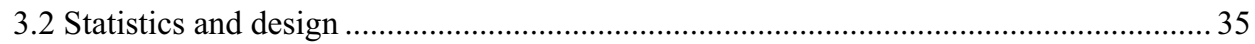

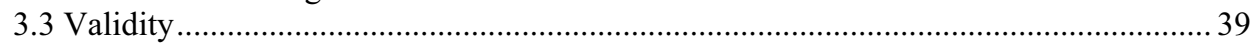

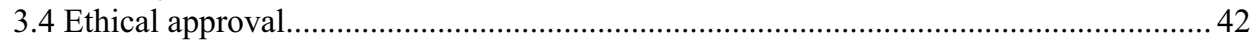

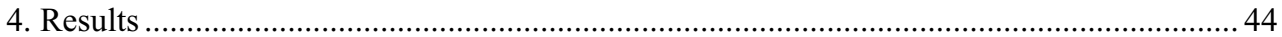

4.1 Paper I. Changes in institutional psychiatric care and suicidal behaviour: a follow-up study of inpatient suicide attempters in Bærum, Norway .............................................. 44

4.2 Paper II. Changes in mental health services and suicide mortality in Norway: an

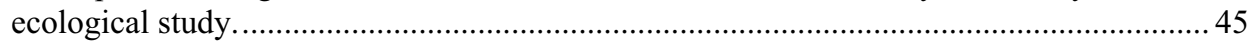

4.3 Paper III. Chain of care for patients who have attempted suicide: a follow-up study

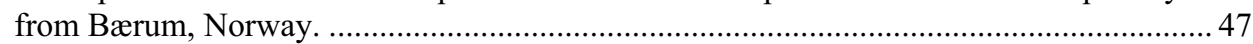

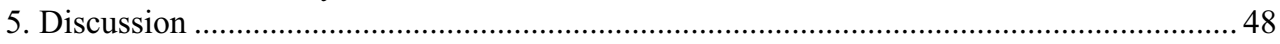

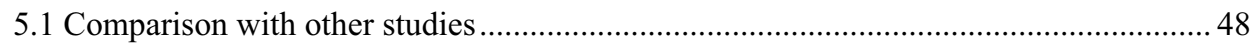

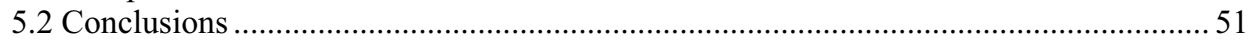

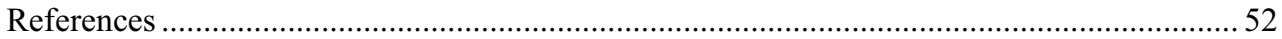




\section{Acknowledgements}

The present study was conducted at the Norwegian Institute of Public Health in the period 1997-2010. Financial support was provided by the Research Council of Norway.

First and foremost, I would like to thank Gudrun Dieserud for giving me the opportunity to do this doctoral dissertation on suicidal behaviours. She has provided me with unique data, supervised me and been a co-author on all my papers. Her comprehensive insight into the suicidal mind and clinical experience in the treatment of suicidal individuals has truly been of value throughout this journey.

I am indebted to my head-supervisor Per-Henrik Zahl for patiently teaching me statistics. In the past four years, he has always taken the time to answer my questions, and in an excellent manner showed me how to write papers in scientific journals. I am also grateful to my cosupervisor Bjørgulf Claussen for critically revising my manuscripts; and for all the support and encouragement he has given me. Thanks to Melanie Straiton and Kathy McKay for improving my English language. I would also like to thank my good colleague Finn Gjertsen for his friendship and for all the interesting academic discussions that we have had.

Warm thanks to Professor Diego De Leo at Griffith University for being co-author on two of my papers and for teaching me how to get the papers published. Warm thanks go also to Kathy, Naoko, Kairi, Urska, Jerneja, Allison and Darrel for making my stay at Griffith University so rewarding.

No study would be possible without data, so I am grateful to Fredrik Jakhelln and Aslaug Fagernes at the general Hospital of Asker and Bærum for participating in the data collection 
procedures. I would also like to thank Fredrik Jakhelln for his contribution as co-author on one of my papers.

Finally, thanks to the directors Johannes Wiik and Arne Holte; and all my colleagues at the Division of Mental Health for making my years at FHI so meaningful. Thanks to family and friends. And last, but certainly not least, this doctoral dissertation would not have been possible without the love, encouragement and patience of my dearest Anne.

Oslo, December 2010 


\section{Summary}

Psychiatric disorders and a history of suicide attempts are the best known risk factors for suicide. Thus, major changes in mental health services and interventions aimed at patients who have attempted suicide might affect the risk of subsequent suicide attempts and suicide. The overall aim of the present thesis was to evaluate the impact of health services on suicidal behaviour, and thereby gain new knowledge relevant for preventing suicidal behaviour.

The thesis consists of three papers. Paper I was designed as a prospective cohort study. We investigated whether individuals admitted to inpatient psychiatric care after a suicide attempt had shorter length of stays in the period 1996-2006 than individuals admitted in the former period 1984-1995. We also considered whether length of stays and time period in which the patients received treatment were related to the risk of subsequent suicide attempts and/or suicide. Individuals hospitalised in the period 1996-2006 had significantly shorter stays than individuals hospitalised in the former period ( $\log \operatorname{rank} \mathrm{P}<0.01)$. However, 'length of stays' and 'period of treatment' were not related to the risk of subsequent suicidal behaviour (adjusted $\mathrm{P}>0.05$ ). Considering that shortened length of stays might increase the likelihood of incomplete recovery, and thereby increased risk of subsequent suicidal behaviour, our interpretation of the results were that shortened length of stays was compensated by improved mental health services, in particular through the major extension of outpatient services.

Paper II was designed as an ecological study. We examined whether increased resources in specialist mental health services in the period 1990-2006 were inversely associated with female and male suicide mortality in five Norwegian health regions. None of the variables that measured mental health service resources (number of man-labour years by all personnel, number of discharges, number of outpatient consultations, number of inpatient days and 
number of hospital beds) were associated with female or male suicide mortality (adjusted P > $0.05)$.

Paper III was designed as a prospective cohort study. The aim was to explore whether a chain of care intervention aimed at individuals who have attempted suicide was effective in preventing subsequent suicide attempts and suicide. In general, a chain of care intervention means the establishment of an integrated health care system which aims to improve quality of care.

We compared the risk of subsequent suicidal behaviour among patients who received a community based chain of care intervention in addition 'to treatment as usual' with patients who only received 'treatment as usual'. We observed no significant differences between the two groups in the risk of a repeated suicide attempt; not within six months (adjusted OR = $1.08 ; 95 \% \mathrm{CI}=0.66-1.74), 12$ months (adjusted $\mathrm{OR}=0.86 ; 95 \% \mathrm{CI}=0.57-1.30$ ) or five years of follow-up (adjusted $\mathrm{RR}=0.90 ; 95 \% \mathrm{CI}=0.67-1.22$ ). Nor did we observe significant differences in the risk of committing suicide (adjusted $\mathrm{RR}=0.85 ; 95 \% \mathrm{CI}=0.46$ 1.57).

Intervention was not assigned to patients for whom the standard aftercare was already deemed sufficient. Thus, we interpreted the results to indicate that this intervention was at least able to render, in terms of outcomes, patients judged to be needier and those judged to be less needy, as indistinguishable. 


\section{List of papers}

The thesis is based on the following three papers (in the text, they will be referred to by their Roman numbers):

Paper I Johannessen HA, Dieserud G, Jakhelln F, Zahl P-H, De Leo D. Changes in institutional psychiatric care and suicidal behaviour: a follow-up study of inpatient suicide attempters in Bærum, Norway. Soc Psychiatry Psychiatr Epidemiol 2009b; 44: 845-51.

Paper II Johannessen HA, Dieserud G, Claussen B, Zahl P-H. Changes in mental health services and suicide mortality in Norway: an ecological study. Manuscript resubmitted for publication.

Paper III Johannessen HA, Dieserud G, De Leo D, Claussen B, Zahl P-H. Chain of care for patients who have attempted suicide: a follow-up study from Bærum, Norway. Manuscript resubmitted for publication. 


\section{Introduction}

Psychiatric disorders are the strongest known risk factor of suicidal behaviour, and a previous suicide attempt is the best known predictor of subsequent suicide attempts and suicide. Hence, successful treatment of psychiatric disorders and successful health care interventions after attempted suicide may prevent future fatal and non-fatal suicidal behaviour.

During recent decades, extensive changes have been implemented in Norwegian mental health services. The present thesis aimed to investigate whether these changes have impacted the risk of suicidal behaviour. In addition, we explored whether a community based chain of care intervention aimed at individuals who have attempted suicide was effective in preventing subsequent suicide attempts and suicide.

The introduction of this thesis begins with a discussion and clarification of how the construct of suicidal behaviour is understood.

\subsection{Nomenclature}

One problem in suicide research is the lack of standard nomenclature with clear conceptual and operational definitions [1-7]. In current suicide research, different researchers apply different conceptions, and thus bewilderment about what constitutes 'suicidal behaviour', 'deliberate self-harm', 'suicide-related behaviour',' parasuicide', 'suicidality' and how to define 'suicide' and 'attempted suicide' is continuously present [2-4]. Consequently, this may obstruct valid comparisons of incidence and prevalence estimations across countries and 
studies [4]. Further, it complicates the validity of risk assessments and measures on treatment effectiveness [4].

As an example: a frequently cited systematic review study by Owens and co-workers [8] aimed to estimate the incidence of non-fatal repetition of self-harm. However, they included studies that addressed different phenomena like 'self-poisoning', 'deliberate self-harm', 'parasuicide', 'attempted suicide' and 'suicidal behaviour'. A closer look at two of the included studies makes it evident that different, and perhaps non-comparable patient groups, were addressed. In the included study by Hawton and co-workers [9], rates of deliberate selfharm were addressed, defined as both self-poisoning, that is "intentional self-administration of more than the prescribed dose of any drug whether or not there is evidence that the act was intended to cause self harm", and self-injury, that is "any injury recognised by hospital staff as having been deliberately self-inflicted". When compared to the included study by Van der Sande and co-workers [10], which addressed attempted suicide, it is easy to see that different patient groups were addressed, because patients who displayed habitual self-mutilation and patients with accidental drug overdoses were excluded in this study.

In 2006, De Leo and co-workers [4] made a comprehensive effort to create a nomenclature for the entire spectrum of suicidal behaviours. This nomenclature is shown in Fig 1. Three broad outcomes are identified: 'fatal suicidal behaviour', 'non-fatal suicidal behaviour with injuries' and 'non-fatal behaviour without injuries'. Three key terms are used as distinguishing components: 'outcome', 'responsibility' and 'intent'. Intent is quantified as any degree that is greater than zero. 


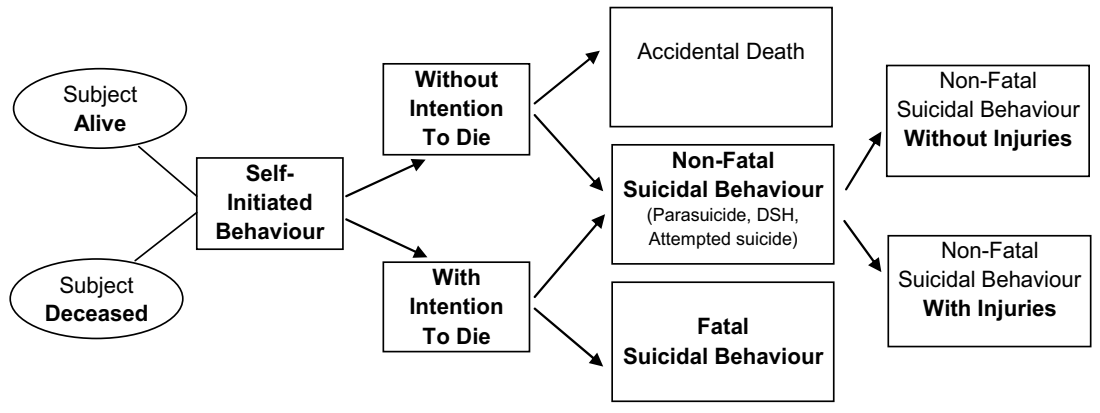

Fig 1. Flow chart of fatal and nonfatal suicidal behaviour. Copied from De Leo and co-workers (2006) [4].

In the nomenclature created by De Leo and co-workers, self-initiated behaviours that are not motivated by the wish to die may be categorised as non-fatal suicidal behaviours. This could be conceived as controversial because one could logically argue that fatal and non-fatal suicidal behaviours are only distinguishable by the outcome. Instead, Silverman and coworkers [3] proposed a different solution than De Leo and co-workers. According to Silverman and co-workers, suicide-related behaviours should be determined by the evidence of intent to die. If the behaviour is intended, it should be categorised as attempted suicide or suicide, dependent on the outcome; if not, the behaviour should be categorised as self-harm or self-inflicted unintentional death. In cases with unknown intent, the behaviour, dependent on outcome, should be categorised as an undetermined suicide-related behaviour or self-inflicted death with undetermined intent.

Empirical research has shown that individuals engaging in behaviour commonly defined as deliberate self-harm, self-poisoning, parasuicide or attempted suicide have a different sociodemographic profile than individuals who commit suicide [11-13]; and it has been suggested that fatal and non-fatal suicidal behaviours are different, although clearly overlapping, phenomena [14]. On the other hand, it is arguable that an operational definition which 
differentiates between fatal and non-fatal behaviours merely by the outcome of the behaviour, would also expectably mean that individuals engaging in such behaviours were more similar on psychological and socio-demographical profiles. However, such a definition could be empirically useless, given the difficulties inherent in ascertaining intent.

In the present thesis, attempted suicide is defined as: "An act with nonfatal outcome, in which an individual deliberately initiates a non-habitual behaviour that, without intervention from others, will cause self-harm, or deliberately ingests a substance in excess of the prescribed or generally recognised therapeutic dosage, and which is aimed at realising changes which the subject desired via the actual or expected physical consequences" [15]. This definition recognises the difficulties inherent in ascertaining intent and excludes habitual or self-mutilating behaviours [4].

Suicide is, in the present thesis, classified by Statistics Norway according to the "International Classification of diseases and Causes of Death (ICD)" taxonomy. In this taxonomy, suicide is a residual mode, that is, to be used when natural, accidental or homicidal causes of death cannot be confirmed [4]. The crucial elements in this process of categorisation are the locus of origin (self-initiated) and the intention (to cause, or not to cause, death) [4]. In the present thesis, suicidal behaviour refers to attempted suicide and suicide as defined above.

\subsection{Epidemiology}

According to the World Health Organization [16-18], suicide is a substantial public health problem. In the year 2000, it was estimated that about 800,000 individuals died from suicide around the world (14.5 suicides per 100,000 person-years) [16]. "Suicide rates vary according to region, sex, age, time, ethnic origin, and, probably, practices of death registration" [19]. In Norway, approximately five hundred and twenty deaths are annually 
registered as suicides (11.3 suicides per 100,000 person-years; based on average figures in the ten year period 2000-2009) [20]. As seen in Fig. 2, the Norwegian suicide rate increased substantially during the 1970 s and 1980s. After the peak in 1988, the total suicide rate dropped by $37 \%$ from 16.8 per 100,000 in 1988 to 12.2 in 1994; after 1994, the rate levelled off to a $-1 \%$ Annual Person Change (APC), calculated as $(\mathrm{RR}-1) * 100 \%(\mathrm{RR}=0.991 ; 95 \%$ $C I=0.986-0.996)$. In the ten year period 2000-2009, men had about three times higher suicide incidence than women $(\mathrm{RR}=2.582 ; 95 \% \mathrm{CI}=2.432-2.742)$.

Fig. 2: Suicide mortality in Norway per 100,000 inhabitants (1970-2009)

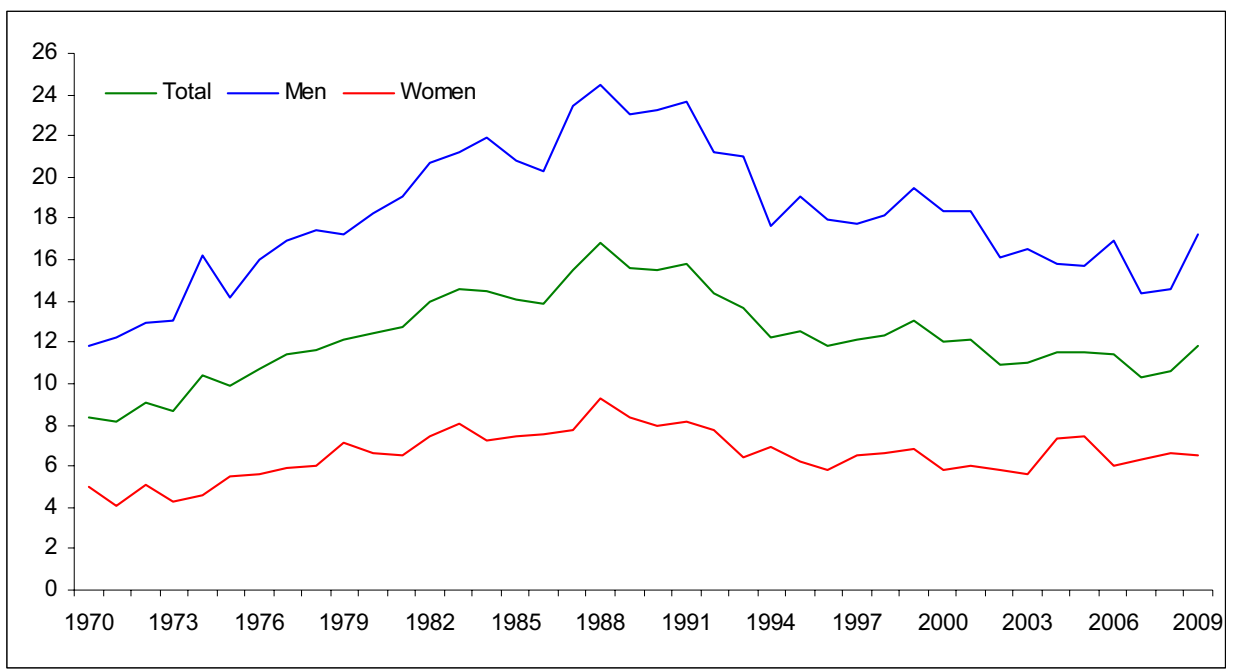

The life-time prevalence of attempted suicide, has in Australia and the United States, been estimated to be above $4 \%[21,22]$. If this estimate holds for Norway as well, there are approximately four attempts for every suicide in Norway. In the municipality of Bærum, Norway, approximately 50 per 100,000 inhabitants attempted suicide annually in the period 2003-2007 $($ Rate $=49.5 ; 95 \% \mathrm{CI}=43.8-55.9)$. If this incidence is representative for the whole country, then approximately five individuals will annually attempt suicide for every individual who dies by suicide in Norway. 
In the period 1984-2007, the incidence of attempted suicide in Bærum declined by $-4.5 \%$ APC $(\mathrm{RR}=0.955 ; 95 \% \mathrm{CI}=948-962)$. Women had about two times higher incidence of attempted suicide than men in this period $(\mathrm{RR}=1.900 ; 95 \% \mathrm{CI}=1.770-2.039)$. As seen in Fig. 3, the total rate had a steep annual decline in the first seven years $(\mathrm{RR}=0.915 ; 95 \% \mathrm{CI}=$ 0.886-0.946) and levelled off from $1991(\mathrm{RR}=0.973 ; 95 \% \mathrm{CI}=0.960-0.985)$. The steep decline observed in the beginning of this period may be real, or may be caused by changes in definitional criteria implemented after 1986.

Fig. 3: Attempted suicide in the municipality of Bærum, Norway, per 100,000 inhabitants (1984-2007)

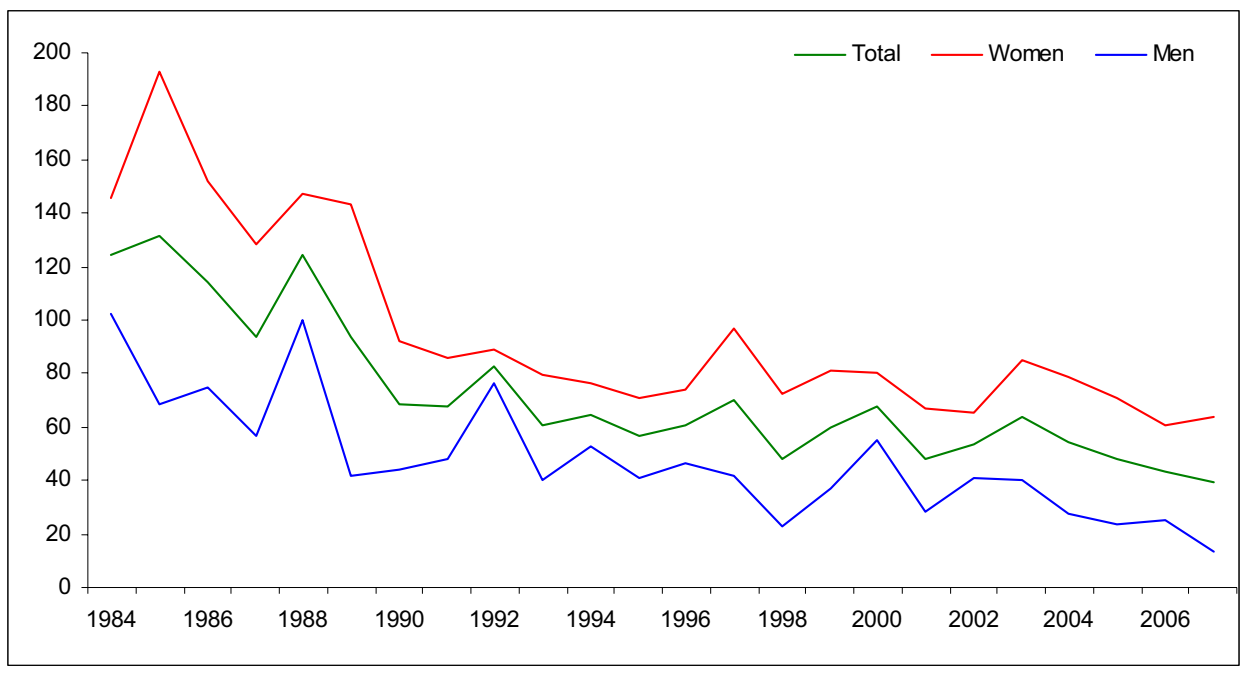

As seen in Fig. 4, the incidence of repeated attempts within 12 months from the first recorded attempt was stable throughout the period 1984-2007 in Bærum. In a systematic review study, Owens and co-workers [8] estimated that about 15\% repeated the attempt within 12 months, and that between $0.5-2 \%$ died by suicide one year after the attempt and above $5 \%$ after nine years. The corresponding figures for Bærum were $12 \%(95 \% \mathrm{CI}=10.7$ to 14.1$)$ for repetition 
within 12 months, and $1.1 \%(95 \% \mathrm{CI}=0.67-1.83)$ for suicide after one year and $4.6 \%(95 \%$ $\mathrm{CI}=3.37-6.22)$ after nine years.

Fig. 4: Annual rate of repeated attempts within 12 months from the first recorded suicide attempt

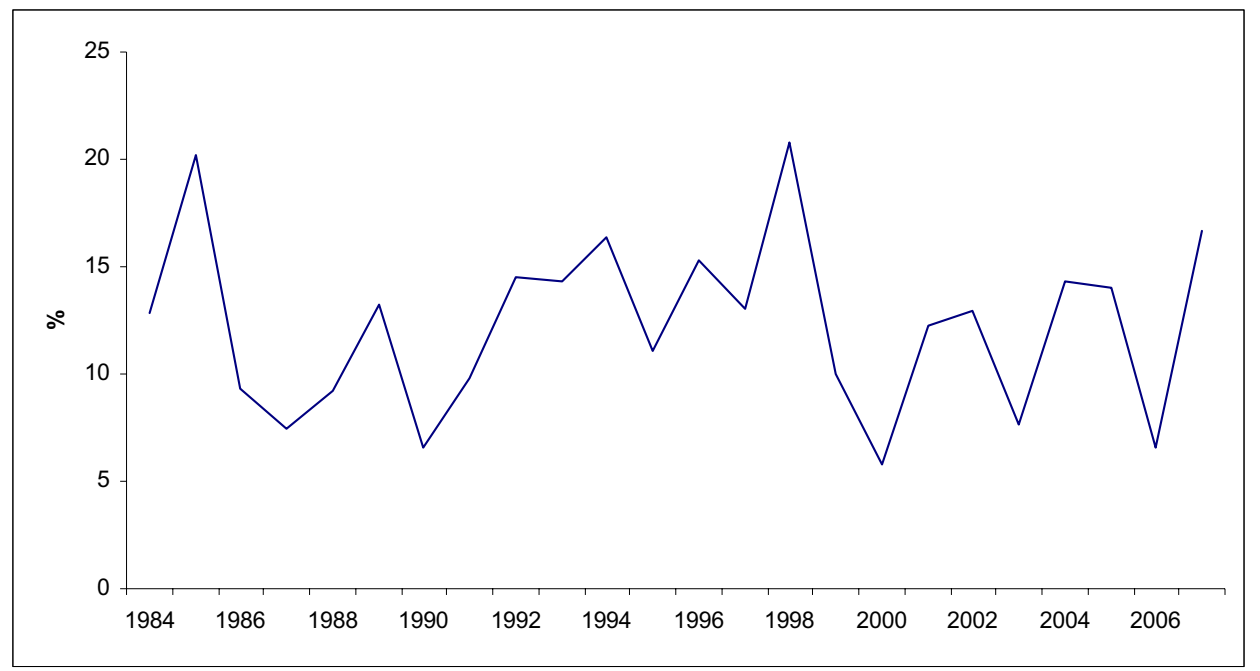

It has been estimated that about $20-40 \%$ of individuals who commit suicide have previously attempted [23-25]. Compared to the general population, individuals who have attempted suicide have about 40 times the risk of dying by suicide (a meta-analysis estimate based on a population of 1700 from three countries; follow-up period between 0 and 20 years) [26]. The risk is found to be highest within six months after the attempt [27]. However, excess suicide risk is also found decades later [28]. In addition, individuals who have attempted suicide are more likely to die prematurely from all mortality causes than individuals in the general population [29]. Within a mean follow-up time of five years, Ostamo and Lonnqvist estimated that mortality of all causes was 15 times that expected among male attempters, and nine times that expected among female attempters [29]. 


\subsection{Risk factors}

Like most behaviour, suicidal behaviour is likely to be a result of a complex interaction of cultural [30-32], social [33-38], psychological [39-42] and biological factors [43-45]. The various factors that contribute to suicidal behaviours can be described in an explanatory model such as the stress-diathesis model (Fig. 5) [19].

Fig. 5. Stress-diathesis model of suicidal behaviour (Copied from Hawton et al. 2009) [19].

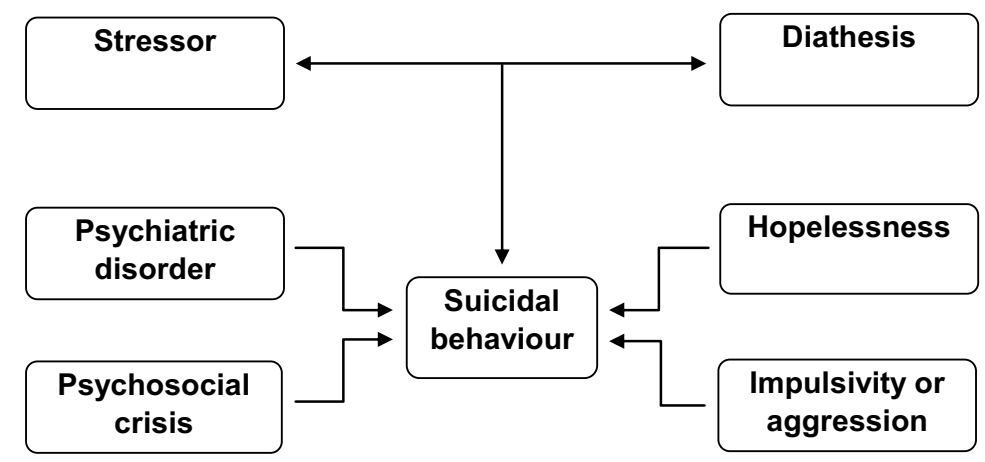

In short, this psychological model supposes that a given biological/genetic vulnerability or predisposition (diathesis), in interaction with a given environment or life event (stressors), will lead to the disorder or behaviour of interest. Proximal stressors like acute psycho-social crisis or psychiatric disorders can, in interaction with distal factors like pessimism, hopelessness, aggression or impulsivity trigger suicidal behaviour [19].

\subsection{Psychiatric disorders}

The vast majority of individuals with a psychiatric disorder do not attempt suicide or die by suicide [24]. Hence, psychiatric disorders are an insufficient condition of suicidal behaviour. Nevertheless, psychiatric disorders are the best known risk factor for suicidal behaviour, that 
is, suicidal behaviour is considerably more frequent among individuals with a psychiatric disorder than among individuals without $[11,12,19,25,26,35,46-50]$.

The classic approach to investigate characteristics of people who have committed suicide is known as the psychological autopsy method $[19,51]$. This method involves retrospective collection of information, usually structured interviews with key informants like family members, relatives and close friends of the deceased, together with examinations of official medical records and interviews with health personnel $[52,53]$. In a review of these studies it was estimated that a diagnosable psychiatric disorder was present in about $90 \%(95 \% \mathrm{CI}=$ 81-98) of people who committed suicide [25]. The relative risk between psychiatric disorders and suicide was found to range from 1.98-6.28 [25, 54-60].

Among the psychiatric disorders, various subtypes of affective disorders have been found to give the highest risk [25]. For instance, the lifetime suicide risk among individuals with a major depressive disorder has been estimated to be $7 \%$ in men and $1 \%$ in females, respectively (combined risk 3.4\%) [61]. To show the consequences of this association, we can estimate the expected number of suicides attributable to major depression in a hypothetical Norwegian cohort of 100,000 men. The 12-months prevalence of major depression in Norwegian men has been estimated to be $4.1 \%$ [62]. Thus, in 100,000 Norwegian men, 4,100 will have a major depressive disorder. Among these, $287(7 \% * 4100)$ will commit suicide. In comparison, the lifetime suicide risk in the total Norwegian male population is $1.178 \%$ (15.5 suicides * 76 expected life-years/ 100,000 person-years), which will result in 1178 suicides. Thus, about $1 / 4(287 / 1178)$ of the suicides in the cohort can be attributed to major depressive disorder. 
Moreover, virtually all psychiatric disorders have been found to increase the risk of suicide, except mental retardation and dementia [26]. Generally, the risk is highest for functional disorders and lowest for organic disorders with substance abuse disorders in between [26]. Further, suicide risk is found to increase with illness severity. In a Norwegian cohort study, Bramnes and co-workers [48] found a dose-response effect of self-reported anxiety and depression problems on suicide mortality. In particular, illness severity that necessitates hospital admission has been strongly associated with suicide [35, 46, 47, 63, 64]. For instance, in a Danish population-based nested case-control register study, it was documented that about $50 \%$ of all those who had died by suicide, had been, or were at the time of death, psychiatric inpatients [46]. Suicide risk has been found to peak in the first week after admission and immediately after discharge [47]. Among inpatients, a profile has been identified for patient groups at particularly high risk, namely patients with previous selfharming behaviour, admission for deliberate self-harm/suicidal ideation, living alone, work stresses at follow-up, compulsory admissions and being out of contact with services after discharge [65].

As with suicide, psychiatric disorders are also the strongest known risk factor for attempted suicide. About $90 \%$ of individuals presented to an emergency unit after attempting suicide had at least one psychiatric disorder $[11,49,50]$. Depression, substance abuse, anxiety disorders and aggressive behaviour disorders have, in particular, been found to distinguish suicide attempters from non-attempters [11-13]. Co-morbidity is common, in particular cooccurrence of mood and substance abuse disorders [66, 67]. 


\subsubsection{How much of the variation in suicide mortality is attributable to psychiatric disorders?}

One approach to answering this question is to estimate the theoretical maximum number of cases that could be prevented if everyone had the same risk as those not exposed to psychiatric disorders. This estimate is referred to as the population attributable risk (PAR). In contrast to risk ratio- and odds ratio estimates, PAR takes account of how prevalent the exposure is [68].

To show how the PAR-estimate accounts for the number of exposed individuals in the population, I will use crude figures presented in the paper: "Psychiatric illness and risk factors for suicide in Denmark" [46]. In this paper, Mortensen and co-workers used Danish registries to study suicide risk in relation to psychiatric hospitalisation. The study had a population-based nested case-control design. In a case-control design, PAR is defined as: $P(E / D) *[(\mathrm{RR}-1) /(\mathrm{RR})]$, where $P(E / D)$ is the proportion of cases exposed to the factor and RR is the risk ratio [68].

Based on crude figures shown in Table 1, the risk of suicide is 78 times greater among individuals recently discharged ( $<30$ days) than among individuals never hospitalised; whereas the risk of suicide is 20 times greater among individuals with a history of hospital admission than among individuals never hospitalised. If a totally successful intervention eliminated the exposure among individuals recently discharged, $6 \%$ of the suicides would be prevented; whereas $46 \%$ of the suicides would be prevented if the intervention was aimed at individuals with a history of admission. Although the risk of suicide is 4 times greater among individuals recently discharged than among individuals with a history of admission, more 
lives would be saved by intervening among individuals in the latter group because more individuals would be under exposure.

Table 1. Crude figures of cases and controls in relation to psychiatric hospitalisation

\begin{tabular}{llll}
\hline & Non-exposed & Ever admitted to ward & Total \\
\hline Controls & 76284 & 3587 & 79871 \\
Cases & 419 & 392 & 811 \\
\hline $\mathrm{OR}=20$ & $\mathrm{PAR}=46 \%$ & \\
\hline
\end{tabular}

\begin{tabular}{llll}
\hline & Non-exposed & Discharged $<30$ days & Total \\
\hline Controls & 79805 & 66 & 79871 \\
Cases & 762 & 49 & 811 \\
\hline $\mathrm{OR}=78$ & PAR $=6 \%$ & & \\
\hline
\end{tabular}

The adjusted PAR of a history of psychiatric hospital admission for suicide was in the study by Mortensen and co-workers estimated to be $44.6 \%$ [46]. In the psychological autopsy studies, the estimated population attributable risk for the relation between any psychiatric disorder and suicide in the general population was estimated to be between $47-74 \%$ [25].

In Norway, based on a random sample of the inhabitants in Oslo, it was estimated that the 12 months prevalence of all psychiatric disorders was 33\%; whereas the lifetime prevalence was $52 \%$ [62]. In addition, statistics show that every year about 75 individuals who are currently in treatment for psychiatric disorders in specialist mental health services die by suicide, accounting for about $15 \%$ of all suicides per year in Norway [69]. Thus, the theoretical suicide prevention potential attributed to successful treatment can be assumed to be substantial. 


\subsubsection{Bias}

Suicide is a rare outcome and is therefore often studied retrospectively (e.g. case-control design), as in the psychological autopsy studies. An important methodological challenge in a retrospective design relates to the fact that exposure information is obtained after the outcome has occurred [70]. This may lead to the systematic error known as recall bias: in retrospect, informants may actively 'search after meaning' or 'explanation' for why the outcome occurred. Thus, it may be that psychiatric disorders are more sought after as an explanation among suicide victims than among controls. Another potential bias in suicide research, independent of design, is the possibility that the coroners may be more likely to return suicide verdicts in those with known psychiatric disorders [25]. In sum, it is important to be aware that systematic errors in suicide research may have led to an overestimation of the association between psychiatric disorders and suicide.

\subsection{The relationship between mental health services and suicidal behaviour}

Psychiatric disorders are probably the most important single factor in the pathway to suicide. Thus, it is reasonable to assume that substantial changes in how mental health services are organised, extended or improved may have an impact on suicide mortality. The key assumption is that successful treatment of a psychiatric disorder will make the individual less likely to commit suicide, given that all other relevant factors are constant. At the societal level the assumption is that more successful treatment of individuals with psychiatric disorders will result in reduced suicide rates, given that all other relevant factors are constant.

In most Western countries, a psychiatric reform labelled de-institutionalisation has been implemented during the last 30-40 years [71, 72]. Three key elements have been identified in the process of de-institutionalisation: 1) traditional psychiatric institutions were downsized 
(de-hospitalisation); 2) alternative services in general hospitals, outpatient services or other settings were established (trans-institutionalisation); 3) community-based inpatient and especially outpatient services were established (de-centralisation) [71, 72]. Although this process has, to some degree, varied by time and country, the main common trend has been a substantial downsizing of beds in traditional large psychiatric hospitals in favour of outpatient services, psychiatric wards in general hospitals and de-centralised psychiatric centres [71].

Few, if any, have argued for the return of the asylum. However, several researchers have related the reduction in psychiatric hospital beds to an observed increase in suicide mortality [73-78]. In a descriptive study of patients in a general hospital psychiatric unit, Basset and Tsourtos [79] observed an increase in attempted suicide and suicide over the period 1988 to 1991. They linked this increase in suicidal behaviour to the closure of traditional psychiatric hospitals. The mechanism outlined was that this closure led to increased demand on clinical facilities in general hospitals; hospitals that were not equipped to cope adequately. They observed that more patients were treated in the general hospital over this period and that length of stays was reduced in order to cope with increased demands without an increase in resources.

In a descriptive study from Denmark, Munk-Jørgensen [77] observed a 100\% increase in suicide mortality among non-organic psychotic patients in the area of de-institutionalisation. In a similarly designed study from Norway, Hansen [75] and co-workers found an increase in suicide mortality among psychiatric patients after the process of de-institutionalisation. The mechanism outlined was related to the necessity of psychiatric hospital care for some patient groups. It was argued that the bed reduction policy has gone too far, and that the result is 
crowded wards and increased use of coercion [74, 77]. In addition, in Denmark it has been shown that newly established mental health services are used by patients that have not previously been treated [77]. In other words, the services provided to compensate for reduced inpatient capacity may be used by a different and new patient group. Thus, it might be that for more severe patient groups, the reorganisation from hospital-based to community-based mental health services has resulted in the unwanted outcome of insufficient treatment, premature discharges and incomplete recovery. Consequently, more of these patients may have committed suicide.

In addition to structural changes in the organisation of mental health services, the accessibility of such services has been linked to variation in suicide mortality [80, 81]. The idea is that extended provision of mental health services will result in more individuals being treated for psychiatric disorders [82], which in turn should result in fewer individuals at increased risk of suicide. In an ecological study from the United States, Tondo and coworkers [81] found that states with higher access to mental health services had lower suicide rates. In Austria, Kapusta and co-workers [80] found that both density of psychiatrists and sales figures of anti-depressants were associated with suicide mortality at the societal level. On the other hand, there are studies that have shown no ecological relationship between variation in mental health services provision and suicide rates [83-85].

\subsection{Changes in Norwegian mental health services}

In the Norwegian democratic welfare state, public authorities are responsible for providing and financing health services [86]. The municipalities have responsibility for the provision of primary health services and the central government has responsibility for the provision of specialised health services. All Norwegian citizens have, by law, the right to necessary and adequate health treatment and care [86]. 
In Norway, the process labelled 'de-institutionalisation' started in the mid-1970s with dehospitalisation [71]. This bed-reduction policy accelerated throughout the 1980s. In the ten year period from the end of 1980 to the end of 1990 , the number of beds in adult mental health institutions was reduced by $35 \%$ [87]. The total reduction of beds continued throughout the 1990 s, mainly by downsizing psychiatric nursing homes.

In the late 1980s, the mental health services in Norway became de-centralised by the establishment of District Psychiatric Centres. The objective was that these services should provide short-term inpatient care, day-centres and outpatient services for the inhabitants in the local community [71]. Psychiatric hospitals and psychiatric wards in general hospitals should now focus on short-term treatment of selected patients not treated by the psychiatric centres in the community. By 1998, district psychiatric services accounted for $20 \%$ of all discharges [71]. In addition, the capacity in adult outpatient services increased substantially throughout the 1990 s, from 83 consultations per 1,000 inhabitants in 1990 to 154 per 1,000 inhabitants in 2000 [88].

In a ministerial report dated 1996-97, Norwegian health authorities expressed concern related to the mental health reform [89]. Although the aptness of closing psychiatric state hospitals was emphasised, it was also underlined that too few alternative services had been established in substitution of hospital facilities. The report concluded by stating that the present Norwegian mental health care system had deficiencies at several levels: 1) Prevention efforts were not extensive; 2) community services and availability of psychiatric specialists were not adequate; 3) mean length of stay in psychiatric institutions were too short; and 4) discharges were often inadequately planned and the follow-up was insufficient. 
A plan for improvement in mental health prevention efforts and services was ratified by the Norwegian parliament in 1999, with targets to be fully reached by the end of 2008 [90]. The expenditures in specialist mental health services had a real growth of $175 \%$ from $1998-2007$ [91]. During 2000-2008, the number of outpatient consultations doubled (from 154 to 308 per 1000 inhabitants) [88]. However, the number of beds in adult psychiatric institutions continued to decrease, from 1.7 beds per 1000 inhabitants in 2000 to 1.2 beds per 1,000 inhabitants in 2008 [88]. In Figure 6-8, changes in Norwegian mental health services during the period 1990-2008 are shown. In Figure 9, suicide mortality from 1988 to 2008 is shown with markers for the implementation of the national plan for suicide prevention [92] and the national plan for improvements in mental health services [89].

Fig 6: Number of bed-days and outpatient consultations per 1000 inhabitants (1990-2008)

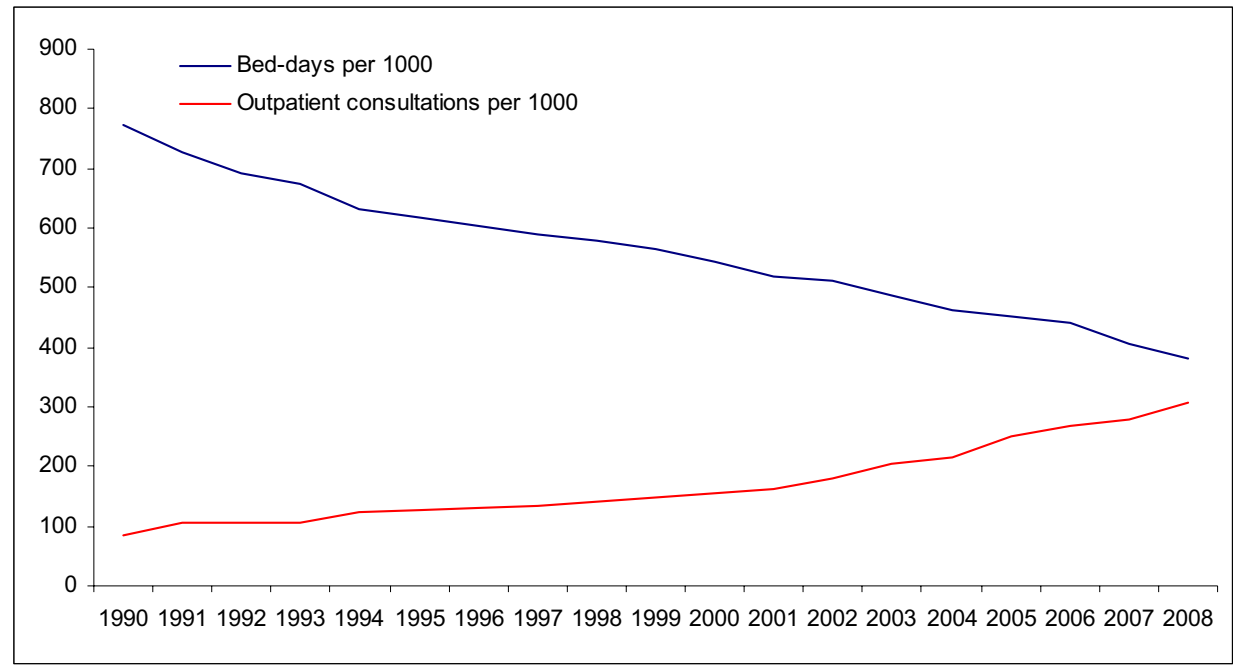


Fig. 7: Number of beds and discharges per 1000 inhabitants (1990-2008)

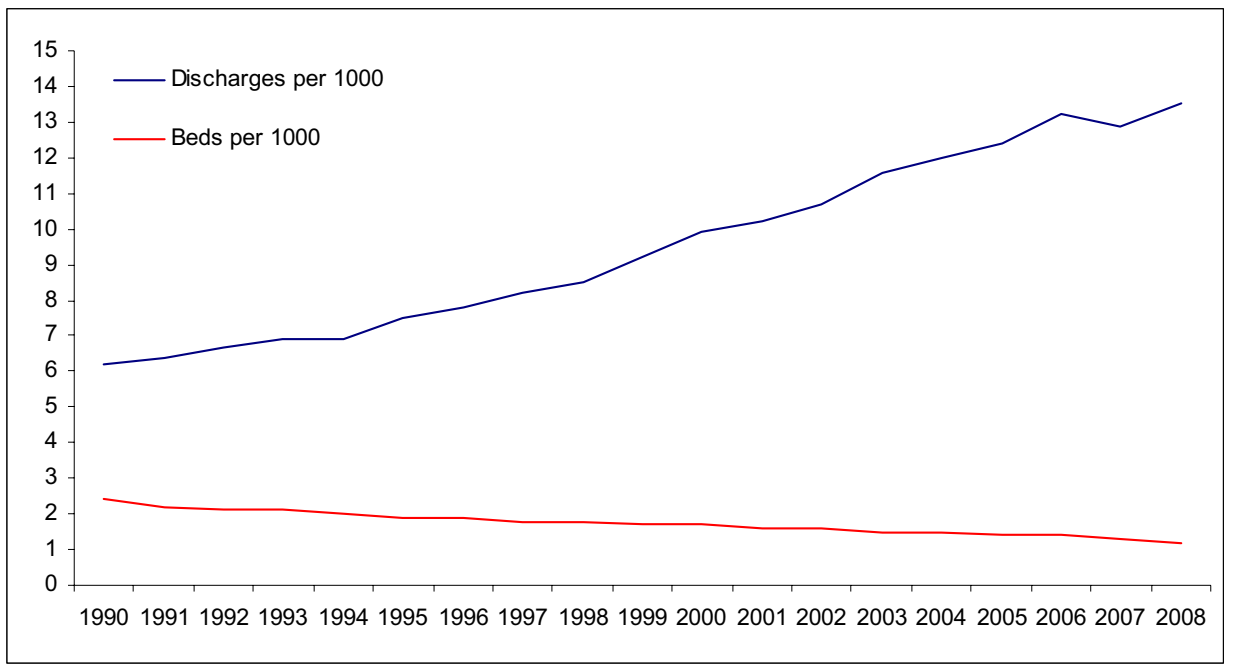

Fig. 8: Number of all personnel per 1000 inhabitants (1990-2007)

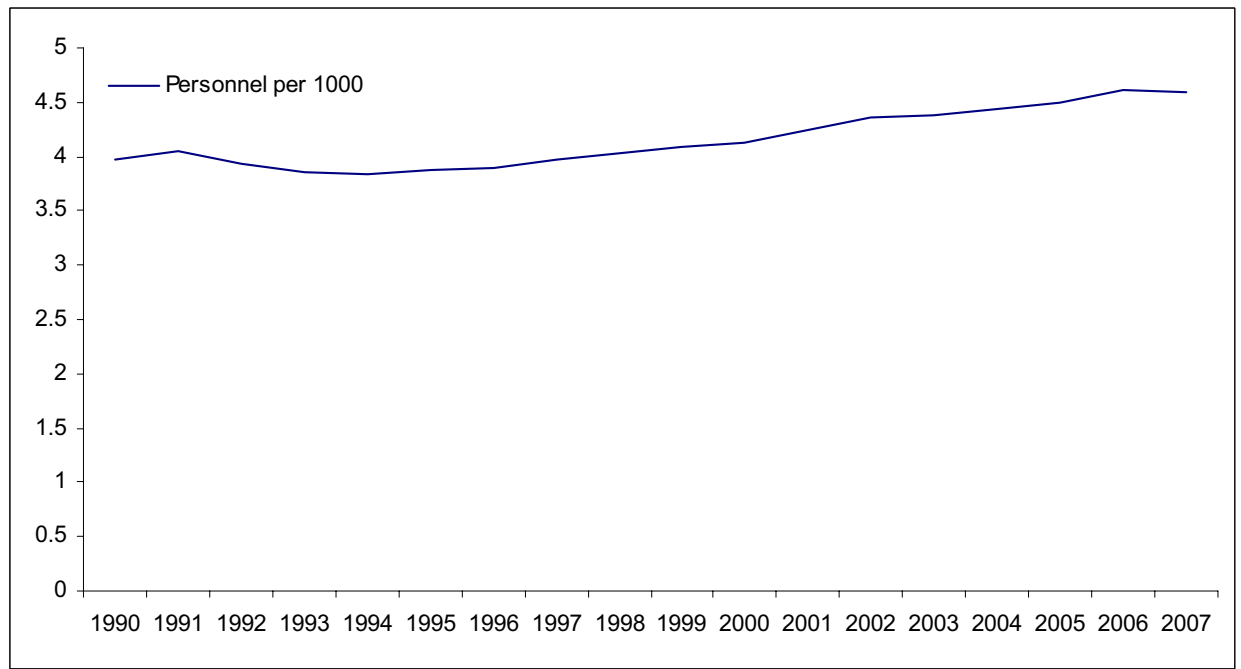


Fig 9. Suicide mortality per 100000 inhabitants

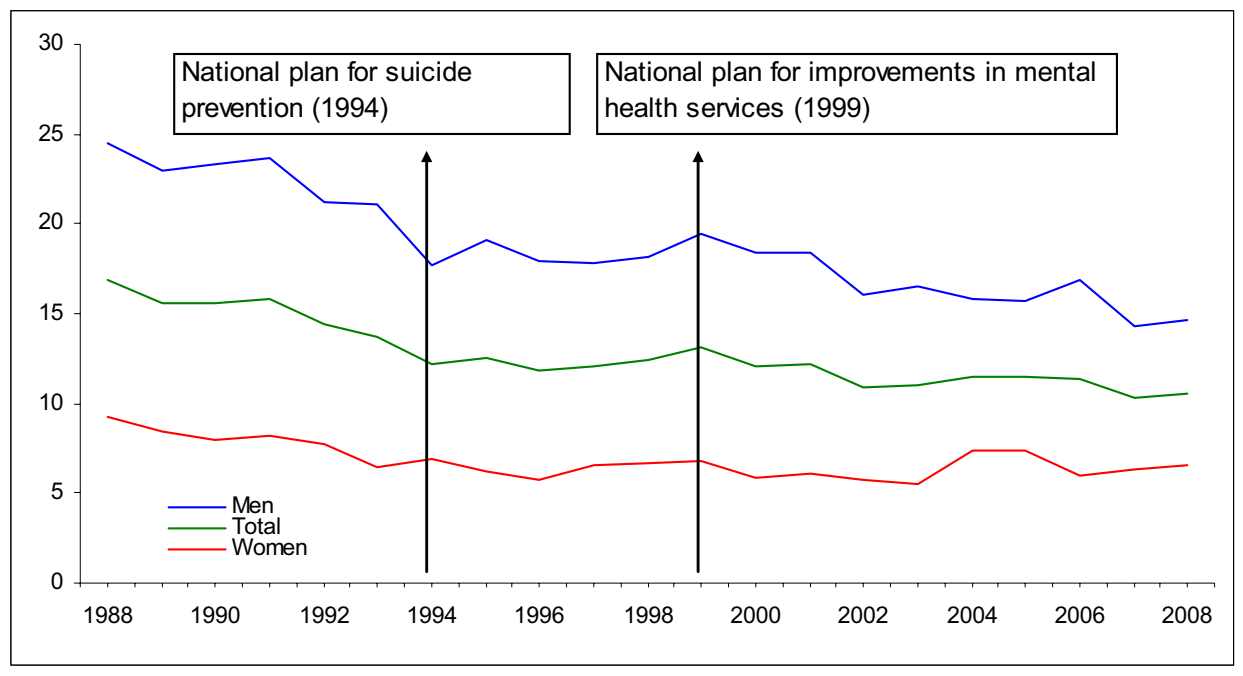

\subsection{Interventions following attempted suicide}

Attempted suicide indicates consistent distress for the individual and involves considerable health care costs [93]. In addition, a previous attempt is associated with a substantial increase in risk for subsequent attempts and suicide. Thus, intervention efforts aimed at preventing subsequent suicidal behaviour among individuals who have attempted suicide are important.

Various psycho-social and pharmacological treatments in preventing subsequent suicidal behaviour have been developed [93]. However, it is difficult to scientifically test the effectiveness of interventions among suicide attempters. This is due to the low rate of suicide. For example, given that the risk of committing suicide in this group is $2.8 \%$, Gunnell and Frankel [94] estimated that a total sample size of almost 45,000 subjects would be needed to demonstrate a $15 \%$ reduction of suicide risk. Therefore, a repeated suicide attempt has been used as a reasonable proxy because it occurs more frequently and is strongly related to suicide. 
Hawton and co-workers [93] conducted a systematic review of the efficacy of treatments in preventing repeated attempts. They searched for trials in the period 1966-1997 and identified 20 studies that met the following inclusion criteria: i) Patients had deliberately harmed themselves shortly before entry into the trial; ii) the trials reported repetition of deliberate self-harm as an outcome measure and iii) the patients were randomised to either intervention or control (standard aftercare). Seventeen of the 20 studies addressed various psycho-social treatments whereas three of the studies addressed pharmacological treatments. The main conclusion drawn from this systematic review was that no firm recommendations about the most effective treatment in preventing repeated self-harm could be made. The evidence was insufficient, mainly due to shortcomings of the trials: too few subjects were included, meaning that statistical power was too low to detect clinically meaningful differences between the experimental group and the control group.

Although few of the trials were statistical significant, Hawton and co-workers identified some promising results to build on in future studies. Four of the twenty trials addressed the effectiveness of problem solving therapy [95-98]. A reduced risk of recurrent self-harm was observed in all four studies (summary $\mathrm{OR}=0.73 ; 95 \% \mathrm{CI}=0.45-1.18$ ) [93]. Promising results were also identified in the two trials that addressed provision of a card allowing patients to make emergency contact with services (summary OR $=0.45 ; 95 \% \mathrm{CI}=0.19$ 1.07). A single trial addressing dialectical behaviour therapy in women with borderline personality disorder showed a significantly reduced risk of repeating self-harming behaviour $(\mathrm{OR}=0.24 ; 95 \% \mathrm{CI}=0.06-0.93)[93,99]$. A single trial that addressed drug treatment with Flupenthixol was also statistically significant $(\mathrm{OR}=0.09 ; 95 \% \mathrm{CI}=0.02-0.50)$ [93]. 
In addition to the trials identified by Hawton and co-workers, Hepp and co-workers [100] conducted a systematic search for trials published between January 1996 and February 2003. Twenty-five trials that met the following inclusion criteria were identified: Patients had attempted suicide, deliberately harmed or poisoned themselves shortly before entry into the trial; the patients were randomised to either intervention or control; the evaluated intervention was psychological or psycho-social; the outcome measure was recurrence of attempted suicide or suicide, deliberate self-harm or self-poisoning. Summary estimates were not computed due to marked methodological differences between trials with similar interventions. Five of the twenty-five identified trials showed a significantly reduced risk of subsequent self-harming behaviour among patients in the intervention group.

Two of these five trials tested psychodynamic interventions. Guthrie and co-workers [101] addressed four sessions of psychodynamic interpersonal therapy delivered in the patient's home. The proportion of repeated deliberate self-poisoning behaviour after six months was $9 \%$ in the intervention group compared to $28 \%$ in the control group $(\mathrm{P}<0.01)$ [101]. The trial of Bateman and Fonagy [102] addressed psychoanalytically oriented partial hospital treatment for patients with borderline personality disorder. They found a statistically significant reduction after twelve and eighteen month follow-ups in both habitual selfharming behaviour as well as attempted suicide for men and women in the intervention group $(\mathrm{P}<0.05)$.

The Dialectical Behaviour Therapy study of Linehan and co-workers, also identified in the systematic review study of Hawton and co-workers above, was the only one in the Cognitive Behaviour Therapy category which reached a statistically significant result [99]. A single trial in the Problem-Solving Therapy category showed a significant reduction in recurrent 
suicide attempts after six months follow-up (among 20 patients, none repeated the attempt in the intervention group, whereas three repeated the attempt in the control group (Fisher's exact test $\mathrm{P}<0.05)$ [98]. This was a five session Problem-Solving Therapy Intervention within one month, carried out by a psychiatric nurse in the patient's home. However, within eight months the difference between the intervention group and the control group was no longer significant. Finally, a four month outreach program conducted by Welu [103], with an initial home visit to establish a relationship followed by weekly or biweekly contacts, showed a reduced risk of a repeated attempt [100]. The results showed that after four months, the proportion of recurrent deliberate self-harm was $4.8 \%$ in the intervention group compared to $15.8 \%$ in the control group $(\mathrm{P}<0.05)[100]$.

None of the identified trials in the review by Hepp and co-workers showed a statistically significant reduced risk of dying by suicide for patients in the intervention group.

In conclusion, the evidence-based knowledge of which treatments or strategies are most effective in preventing suicidal behaviour is still limited [93, 94, 104, 105]. This conclusion is also in line with a Norwegian health technology assessment (systematic review study), which evaluated suicide preventive efforts in specialist mental health services [106]. Hence, "there is considerable need for research into the effects of the different kinds of interventions offered suicidal patients" [106].

Recently, Hvid and Wang [107] published a quasi experimental study on the effectiveness of an outreach intervention aimed at individuals who had attempted suicide. They found that individuals in the intervention group, who were offered follow-up care by a rapid response outreach program, had a lower rate of repeated suicide attempts than the control group $(\mathrm{RR}=$ 
$0.43 ; 95 \% \mathrm{CI}=0.23-0.80$ ). According to Hvid and Wang, this intervention is likely to be acceptable for the patients and affordable for the community, and consequently available for more patients. Moreover, other studies have also indicated the positive effects of interventions that practice active outreach and contact maintenance on a regular basis after a person attempts suicide, e.g. the trials of Guthrie [101], Salkovskis [98] and Welu [103] mentioned above.

\subsection{The Bærum Model}

In a municipality neighbouring the Norwegian capital, a suicide intervention model, similar to the one studied by Hvid and Wang, has been in effect since 1983. In this model, a rapid response intervention is created through collaboration between the general hospital of Asker and Bærum, the municipal suicide prevention team, and community health and social services as well as mental health specialist services located in Bærum [108]. On presentation at the hospital or emergency unit, patients who have attempted suicide receive acute lifesaving treatment and medical monitoring. Thereafter, a hospital-based suicide prevention team, including social workers and a liaison psychiatrist, is notified. This team helps the patients through crisis intervention and evaluates the patients' psycho-social functioning and risk for suicide. Appropriate measures are then taken with the patients' cooperation. These measures can include referrals to psychiatric inpatient and various outpatient services, including mental health treatment, substance abuse treatment, family counselling and various social services.

All patients who are not immediately admitted to psychiatric inpatient wards, after receiving emergency treatment are evaluated for referrals to the community suicide prevention team, in addition to 'treatment as usual'. The community team and the hospital team collaborate to 
ensure a joint evaluation of the situation, to make appropriate referrals, and to make all parts of the follow-up effective as soon as possible (this is known as the chain of care). The main patient groups eligible for referrals to the suicide prevention team are as follows:

- Patients in need of outpatient mental health and social services not otherwise established by the hospital team.

- Patients in ongoing outpatient treatment who are in need of extra support

- Patients and family or significant others who are in relational conflicts and in need of extra support.

- Patients who have previously dropped out of mental health treatment and need motivation to attend again.

The community suicide prevention team includes public health nurses and a psychologist. The psychologist is the supervisor of the public health nurses and leader of the team. The nurses organise the work in relation to patients, in consultation with the psychologist. A particular emphasis is placed on the suicidal person's need for a supportive helper. On average, $50-60 \%$ of the attempters deemed eligible for the community team are referred to this follow-up yearly.

If patients agree to be assisted by this team, a public health nurse contacts them shortly after discharge. These nurses act as "ombudsmen" [109]. The main aim is to ensure that the patients are given sufficient follow-up care by specialist mental health services or community health/social services within an acceptable period of time following hospital discharge. Further, the nurse motivates the patient to accept treatment and to better adhere to treatment appointments. If patients drop out of treatment, the nurse tries to get them back into treatment 
or establishes a more suitable therapeutic plan in collaboration with the patient and the health services.

In addition, the nurse fulfils the role of supporting the patient in between general hospital discharge and established aftercare. The nurse gives the patient "psychological first aid", problem-solving counselling, and cooperates with the patient's social network. Although the main aim is reached when a treatment program is established, the patient is followed-up by the nurse for approximately one year in order to secure continuity, treatment compliance and social support.

The intervention offered by this team is not regarded as stand-alone treatment, but rather as a service offered in addition to established health and social services; it is not a substitute of any other mental health service. If the standard follow-up treatment is deemed to be sufficient by the hospital team, the community team is not called upon. Patients are in any case, free to reject assistance from the community team. 


\section{Aims}

\subsection{Main Aim:}

To evaluate the impact mental health services may have on suicidal behaviour, and thereby gain new knowledge relevant for preventing suicidal behaviour.

\subsection{Specific aims:}

- Paper I: To investigate whether individuals admitted to inpatient psychiatric care after a suicide attempt had shorter length of stays in the period 1996-2006 than in the former period 1984-1995; and to study if length of stays and period of treatment were associated with increased risk of subsequent suicide attempts and/or suicide

- Paper II: To examine whether variation in mental health service resources were associated with suicide mortality in five Norwegian health regions in the period 19902006.

- Paper III: To explore whether a chain of care intervention aimed at individuals who have attempted suicide was effective in preventing subsequent suicide attempts and suicide. 


\section{Materials and methods}

\subsection{Data sources}

\section{Paper I \& III}

The foundation data for Paper I and III comprised of unselected individuals who were residents of the municipality of Bærum and admitted to the general hospital after a suicide attempt. These data have been consecutively collected since 1984 and are based on records from the local general hospital and the Municipal Health Services Office in Bærum [110]. All cases are classified in cooperation by the chief social worker, the liaison psychiatrist and the community psychologist. Further, a quality control auditing was performed by rechecking all entered data. The definitional criteria for 'attempted suicide' were similar to those of 'parasuicide' used in the WHO/EURO Multicentre Study on Suicidal Behaviour: “An act with nonfatal outcome, in which an individual deliberately initiates a non-habitual behaviour that, without intervention from others, will cause self-harm, or deliberately ingests a substance in excess of the prescribed or generally recognised therapeutic dosage, and which is aimed at realising changes which the subject desired via the actual or expected physical consequences" [15].

In Paper I, eligible cases were all individuals admitted to inpatient care at the local psychiatric hospital after emergency treatment at the general hospital between 1 January 1984 and 31 December 2006. Data regarding psychiatric hospital stays were collected by linking the personal identifier of patients who had made a suicide attempt, to the medical record base of the local psychiatric hospital. Personal identifier refers to an 11-digit code which comprises a person's date of birth and a unique national identification number. A total of 1,574 individuals were registered for a suicide attempt in this time period. Of these, 330 made a suicide attempt that was followed by psychiatric inpatient care. 
In Paper III, cases were individuals admitted to the general hospital after a suicide attempt between 1 January 1984 and 31 December 2007. A total of 1,616 individuals were registered for a suicide attempt in this period. Of these, 1,311 were eligible for an evaluation to be referred to the suicide prevention team.

In both Paper I and III, data on mortality of all causes were collected by linking the personal identifier of individuals who had made a suicide attempt to the computerised Causes-ofDeath registry at Statistics Norway. The last date of mortality information in both Papers I and III was 31 December 2003.

\section{Paper II}

In Paper II, aggregated data on suicide mortality, specialist mental health services, unemployment and educational level for all Norwegians were provided by Statistics Norway. Aggregated data on sales figures of pure alcohol in litres were provided by the Norwegian Institute for Alcohol and Drug Research. Sales figures of antidepressants were provided by the Wholesales Register in Norway. All data used in this study are openly available and can be downloaded at Statistics Norway [20] and Norwegian Institute for Alcohol and Drug Research [111], except data on sales of antidepressants, which can be provided by the pharmaceutical Wholesales Register in Norway by request [112].

\subsection{Statistics and design}

\section{Paper I \& III}

In both Paper I and III, the outcome variables were a repeated suicide attempt and suicide. In Paper I, a repeated suicide attempt was defined as a new attempt within 12 months from the date of psychiatric hospital discharge. In Paper III, a repeated suicide attempt was defined as 
a new attempt within six months, twelve months and five years from the date of the first recorded suicide attempt. In both Paper I and III, suicide was classified according to the International Classification of Diseases Eight Revision (ICD-8) prior to 1986, according to the ICD-9 from 1986-1995 and according to the ICD-10 from 1996 onwards.

In Paper I, the explanatory variables of interest were length of psychiatric hospital stays and period of treatment. Length of hospital stays were continuous, measured in days from the date of admittance to the date of discharge. The period of treatment variable was dichotomous, individuals hospitalised in the period 1984-1995 were coded as the reference category. Log Rank tests were used to determine if length of hospital stays was shorter in the period 1996-2006 than in the former period 1984-1995. The rationale of the cut-off was based on the time in which the reduction in hospital beds levelled off (the mid 90's). KaplanMeier survival curves were used to show the length of stays in the two periods. Logistic regression analyses were computed to estimate the risk of a repeated suicide attempt within the 12 months following psychiatric hospital discharge. We adjusted for 'sex', 'age', 'diagnosis', 'marital status' and 'employment status'. Data were also analysed separately for men and women. Survival curves were used to show the time in days from psychiatric hospital discharge to death by suicide in the periods 1984-1995 and 1996-2006.

In Paper III, the explanatory variable of interest was 'suicide prevention team assistance'. This variable was dichotomously coded with 'no suicide prevention team assistance' as reference category. Logistic regression analyses were computed to estimate the risk of a repeated suicide attempt within six and 12 months following the first recorded suicide attempt. Cox regression analyses were computed to estimate the risk of a repeated suicide attempt within five years of follow-up and to estimate the risk for suicide. We adjusted for 
'sex', 'age', 'previous attempt', 'aftercare referral', 'marital status' and employment status' in the regression analyses. Data were also analysed separately for men and women.

In the Cox regression analyses, the individuals were followed for different lengths of time. When the outcome was a repeated suicide attempt, the period of risk was estimated in months from the date of the first recorded suicide attempt to the occurrence of a new attempt, or to the end of the five year follow-up period or to the end of the study (31 December 2008), whichever happened first. When the outcome was suicide, the period of risk was estimated in months from the date of the first recorded suicide attempt to death by all causes or to the end of study (31 December 2003), whichever happened first.

In both Paper I and III, SPSS software was used in all analyses. Both papers were designed as prospective cohort studies.

\section{Paper II}

In Paper II, the outcome variable was female and male suicide mortality in Norway, measured in yearly figures according to ICD-codes. The explanatory variables of interest were 'number of man-labour years by all personnel per 1,000 inhabitants', 'number of discharges per 1,000 inhabitants', 'number of outpatient consultations per 1,000 inhabitants', 'number of inpatient-days per 1,000 inhabitants' and 'number of hospital beds per 1,000 inhabitants'. Regional figures were available from 1998 onwards. For the period before 1998, figures for the whole country were used.

The number of inpatient-days is calculated by subtracting the patient's date of discharge from the date of hospital admittance, that is, the number of days a patient remains in hospital [113]. The number of beds is a calculation of accessible beds in the institutions as of 31 December 
each year [113]. In contrast to bed-days, the number of beds is a measure of the institutions' treatment capacity [113]. The number of discharges is administrative episodes, that is, the same patient can be discharged more than once in a year [113]. Outpatient consultations "include consultations carried out in outpatient clinics or in psychiatric institutions, giving reimbursement from the state" [113]. The total number of man-labour years is estimated as: "the number of full-time jobs and part-time jobs calculated as full-time equivalents adjusted for doctor-certified sickness absence and maternity leave" [113].

Adjustments were made for health region, sales of alcohol, sales of antidepressants, unemployment, and education. In addition, we checked for linear trends. National sales of alcohol were measured in pure litre per inhabitant over the age of 15 . The figure of alcohol sales for the year 1998 was missing. The figure for this year was imputed as the average of the figures in 1997 and 1999. Total national sales of antidepressants (the ATC group N06A) were standardised in defined daily doses (DDD)/1000 inhabitants/day. Education was measured in yearly regional figures of the proportion of inhabitants per 100 with lower and higher college or university education. Unemployment was measured in yearly regional figures of the proportion of inhabitants per 100 unemployed.

Crude rate estimates and Poisson regression were used to measure the impact of changes in mental health services' resources on suicide mortality during the period 1990-2006. Poisson regression has been shown to be a viable and attractive method for quantifying the time trends of rare discrete outcomes like suicide [114].

Separate analyses were computed for females and males. We tested each Poisson model for over-dispersion by comparing the deviance with its degrees of freedom. The deviance is a 
measure of the discrepancy between observed and fitted values [114]. By comparing the deviance with its degrees of freedom, a goodness of fit measure is provided [114]. If the goodness of fit test is significant, the model is inappropriate [114]. All of the computed models showed good model fit $(\mathrm{P}>0.19)$.

We substituted missing regional data with average national data. To examine if this procedure had unwanted bearings on the results, we fitted national models with complete data and compared the results with the regional models. In addition, to rule out the possibility of a collinearity problem, we also computed an adjusted model in which each mental health service variable was analysed separately.

We used Stata software to compute Poisson regression analyses. The study had an ecological design.

\subsection{Validity}

\section{Paper I \& III}

A major advantage with the study design of Paper I and III is that exposure information was obtained before the outcome had occurred. In contrast to cross-sectional designed studies, causal inference is possible because one can be certain that the outcome occurred after the exposure in time. And unlike case-control designed studies, recall bias is not a problem.

A limitation in Paper I was the low level of statistical power. There were 50 cases of repeat attempts. Hence, the probability of making a type II error (failure to reject a false null hypothesis) is relatively high. 
A problem in both Paper I and III, was that in order to be recorded, the repeated attempt had to lead to treatment in an emergency unit or hospital admittance in Asker \& Bærum.

However, in Paper III, we used a narrow time interval of six months in order to control for this deficiency. It is doubtful that a substantial proportion of individuals moved to another part of the country within six months after the index attempt. Further, the results were similar for a repeated attempt within both six and 12 months. Hence, it is unlikely that this limitation have biased these two studies.

In Paper III, selection bias is a problem. Both self-selection by patients and selection by health care personnel may have biased the study. Patients were free to choose whether or not to accept the assistance offered by the community suicide prevention team. Furthermore, health care personnel could choose not to offer team assistance when circumstances were considered inappropriate or of no particular concern. This kind of bias can only be avoided by randomisation. Since patients were not randomised, we know a priori that firm conclusions cannot be drawn.

\section{Paper II}

In epidemiology, ecological-level data are often considered as less valid than individual-level data. According to Schwartz [115], ecological studies are conceived as "crude attempts to ascertain individual level correlations", that is, as substitutes when individual level-data are unavailable. Further, the flaws in ecological models "limit their usefulness to hypothesis generations". The flaws in ecological models are generally attributed to a problem known as the 'ecological fallacy'. Ecological fallacy refers to the logical fallacy in cross-level inference, that is, to infer from the group level to the individual level, or from the individual level to the group level. It has been confirmed in several studies "that the correlation coefficient between 
two individual-level variables is generally not the same as that between those same variables for aggregates into which the individuals are grouped" [115].

However, this is neither a statistical problem, nor a problem of measuring associations, but rather it is a problem of construct validity. That is, the assumption that because a group has a specified characteristic, the members of that group will have the same characteristic. An illuminating example is given in the paper by Schwartz [115]:

\footnotetext{
"A hung jury is a jury that is indecisive, it cannot decide whether the accused is guilty or innocent. However, to deduce that members of such a jury are indecisive would be absurd. Members of a hung jury are very decisive, so much that they cannot be persuaded to change their mind."
}

Since ecological fallacy is a problem of cross-level inference, it is not a problem inherent in ecological studies. For instance, the problem of ecological fallacy commonly occurs in individual-level studies when proxy measures are used. For instance, assume that one wants to adjust for diet in a study of the association between a given exposure and disease. Data on dietary habits turns out to be unavailable; therefore data on education is used as a proxy measure of diet. The logic is that groups with different educational levels will exhibit different dietary habits. However, doing so will involve an ecological fallacy, because it is assumed that the individual exhibits similar dietary habits as the group the individual is a part of (this example is adapted from Schwarts, 1994) [115]. The result will most likely be measurement errors and a poor estimation of dietary habits.

In Paper II, ecological fallacy is not a problem. If our research aim had been to determine whether successful psychiatric treatment lowered the risk of dying by suicide, then we would have had a problem of ecological fallacy. However, the question of interest was if increased 
resources in mental health services and a greater number of individuals being treated would have an annual dose-response impact on the national suicide rate. This question cannot be answered by individual-level data. Hence, our ecological model is not a substitute for a more appropriate individual-level model.

Complex phenomena are explained by mechanisms at a finer tuned level, e.g. depression can be explained by a decrease in serotoninergic neurotransmission. Hence, the reason for investigating a possible association between increased resources in mental health services and suicide mortality is the probability that successful treatment of individuals with psychiatric disorders will reduce the risk of dying by suicide. However, even if this mechanism is empirically true at the individual level, we cannot simply suppose the same relation at the societal level, as shown above.

A substantial advantage with an ecological study is that selection bias is not an issue. In addition, the changes in the exposure variables of interest are substantial over the period 1990-2006. This gives the design a natural experimental character, that is, competing explanatory variables can be assumed to be constant. Hence, the internal validity is high because of reduced problems with confounding.

\subsection{Ethical approval}

In Paper I and III, the data set used contained highly sensitive information. Thus, data security and confidentiality was important. The Norwegian Institute of Public Health has strict rules on how to handle such data and these have been followed. Further, the study was approved by Regional Committee for Medical Research Ethics and licensed by the Data Inspectorate. We also obtained an exemption from the duty of confidentiality by the Directorate of Health 
Affairs. Finally, a Data Handling Treaty between the Hospital of Asker \& Bærum and the Norwegian Institute of Public Health was obtained. 


\section{Results}

\subsection{Paper I. Changes in institutional psychiatric care and suicidal behaviour: a follow-up study of inpatient suicide attempters in Bærum, Norway}

The purpose of this paper was to examine if suicide attempters admitted to inpatient care had shorter length of stays in the period 1996-2006 than patients admitted in the former period 1984-1995; and to examine if 'length of hospital stays' and 'period of treatment' were associated with increased risk of subsequent attempts and/or suicide.

Individuals admitted in the period 1984-1995 had significantly longer hospital stays than individuals admitted in the period 1996-2006 (Log Rank: $\mathrm{P}<0.001$, patient/days analysed from 0 to 365 days). The length of hospital stays was also significantly different in the two periods, both when patient/days were censored at 100 days $(\mathrm{P}<0.001)$ and when patient/days were analysed from 100 to 365 days $(\mathrm{P}<0.02)$. This means that length of stay was reduced for both short and longer-stay patients in the second period. The median stay in the first period was 31 days $(95 \% \mathrm{CI}=21-41)$, whereas the median stay in the second period was 19 days $(95 \% \mathrm{CI}=15-24)$.

Among individuals admitted in the period 1984-1995, 18\% made a subsequent attempt within 12 months from discharge, whereas 13\% made a subsequent attempt in the period 1995-2006. Both length of hospital stays (adjusted OR $=0.99 ; 95 \% \mathrm{CI}=0.98-1.00$ ) and the period in which the individuals received treatment (adjusted $\mathrm{OR}=0.72 ; 95 \% \mathrm{CI}=0.28-1.83$ ) were unrelated to the risk of a subsequent suicide attempt within 12 months from discharge. The results were similar in the crude analysis and when adjustments for sex, age, diagnosis, marital status and employment status were made. 
Considering type II error, it could be hypothesised that increasing the length of hospital treatment may, to a certain extent, have a protective effect on suicide attempt repetition, at least for women. When women were analysed separately, data indicated that a 10 day increase in the length of hospital stays reduced the adjusted odds ratio of repeating a suicide attempt by $10 \%$. However, the argument also holds for the variable 'time period of treatment'. The data indicated that individuals who received treatment in the period 19962006 compared with the period $1984-1995$ had a $28 \%$ decrease in the adjusted odds ratio of making a repeat attempt. Consequently, although the length of hospital stay has decreased significantly during the study period, and the fact that long hospital stays may have a protective impact on the risk of repeating a suicide attempt, data indicated that suicide attempters who received treatment in the period 1996-2006 were not at increased risk of suicide attempt repetition.

We had too few cases of suicide in order to determine associations between length of hospital stays and suicide, and period of treatment and suicide, respectively. However, survival curves showed that the time in days from discharge to suicide was extensive in both periods, which may indicate that it is unreasonable to infer that deficits in hospital treatment caused the suicides.

\subsection{Paper II. Changes in mental health services and suicide mortality in Norway: an ecological study.}

The purpose of this paper was to investigate whether increased recourses in mental health services were associated with reduced female and male suicide mortality in five Norwegian health regions during the period 1990-2006. 
From 1990-2006, the total suicide rate in Norway declined by $26 \%$. Most of the decline was observed from 1990-1994 $(\mathrm{RR}=0.94 ; 95 \% \mathrm{CI}=0.91-0.97)$, thereafter the rate levelled off $(\mathrm{RR}=0.99 ; 95 \% \mathrm{CI}=0.98-1.00)$. In contrast, the major changes in the health service variables were observed in the end of the period 2000-2006.

All of the variables that measured resources in specialist mental health services (number of man-labour years by all personnel, number of discharges, number of outpatient consultations, number of inpatient-days, number of hospital beds) were unrelated to female and male suicide mortality after adjusting for competing explanatory factors (adjusted $\mathrm{P}>0.05$ ). This result was true for all of the models that we computed.

Among women, the variables that best explained the variation in suicide mortality were health region, sales of alcohol (adjusted $\mathrm{P}=0.01)$ and sales of antidepressants (adjusted $\mathrm{P}=0.03)$. A one-unit (one litre pure alcohol per inhabitant per year) increase in sales of alcohol predicted a $41 \%$ increase in suicide mortality (adjusted $\mathrm{RR}=1.41 ; 95 \% \mathrm{CI}=1.18-1.72$ ), and a one unit (one defined daily doses/1000 inhabitants/day) increase in sales of antidepressants predicted a $2 \%$ decline in suicide mortality (adjusted $\mathrm{RR}=0.98 ; 95 \% \mathrm{CI}=0.97-1.00$ ).

Among men, the variables that best explained the variation in suicide mortality were health region, education (adjusted $\mathrm{P}=0.01)$ and unemployment (adjusted $\mathrm{P}=0.01)$. A one unit $(1 \%)$ increase in the proportion of men with college or university education predicted a $14 \%$ decline in suicide mortality (adjusted $\mathrm{RR}=0.86 ; 95 \% \mathrm{CI}=0.79-0.94)$, and a one unit $(1 \%)$ decline in the proportion unemployed men predicted a $9 \%$ decline in suicide mortality (adjusted $\mathrm{RR}=0.91 ; 95 \% \mathrm{CI}=0.85-0.97)$. 


\subsection{Paper III. Chain of care for patients who have attempted suicide: a follow-up study from Bærum, Norway.}

The purpose of this paper was to explore whether the chain of care intervention aimed at patients who have attempted suicide was effective in preventing subsequent suicide attempts and suicide.

Among the patients who received the intervention in addition to 'treatment as usual', $9 \%$ repeated the attempt within six months, and $12 \%$ repeated the attempt within 12 months of follow-up; among the patients, who only received 'treatment as usual', $7 \%$ repeated the attempt within six months, and $11 \%$ repeated the attempt within 12 months of follow-up.

The regression analysis showed no significant differences in the risk of a repeated suicide attempt between patients who received this intervention and patients who did not; not within six months $($ adjusted $\mathrm{OR}=1.08 ; 95 \% \mathrm{CI}=0.66-1.74), 12$ months $($ adjusted $\mathrm{OR}=0.86 ; 95 \%$ $C I=0.57-1.30$ ) or five years of follow-up (adjusted $R R=0.90 ; 95 \% C I=0.67-1.22$ ). Nor did we observe significant differences in the risk of committing suicide (adjusted $R R=0.85$; $95 \% \mathrm{CI}=0.46-1.57)$. The results were similar in the crude analysis and when adjustments for sex, age, previous attempts, aftercare referrals, alcohol misuse, marital status and employment status were made.

Intervention was not assigned to patients for whom the standard aftercare was already deemed sufficient. Thus, those requiring more help at time of the suicide attempt were, after the intervention, rendered indistinguishable in terms of outcomes, from those not initially requiring the additional help. 


\section{Discussion}

The present study has evaluated the impact of mental health services on suicidal behaviour. In Paper I, we found that the move towards shorter length of stays among inpatient suicide attempters did not increase the risk of subsequent suicidal behaviour. In Paper II, we found that substantial changes towards increased resources in Norwegian mental health services were unrelated to female and male suicide mortality over the period 1990-2006. Finally, in Paper III, we found that the chain of care model for patients who have attempted suicide may be effective in preventing subsequent suicidal behaviour.

\subsection{Comparison with other studies}

\section{Paper I}

We searched Medline up until October 2010. We used the search term 'suicide' and 'attempted suicide' in combination with 'length of stays'. The search resulted in 262 hits. None of these studies used a prospective design to study the effect of length of stays among inpatient suicide attempters on the risk of subsequent suicidal behaviour. However, length of stays and risk of suicide has been studied among patients in the general psychiatric population with varying results $[47,116,117]$. Qin and Nordentoft [118] used longitudinal Danish registers and reported that patients who had shorter than median length of stays had an increased risk of committing suicide. The authors suggested that premature discharge and incomplete recovery might explain the observed additional suicide risk in the immediate postdischarge period. On the other hand, in a retrospective population based cohort study, Ho [116] found no support for the premature discharge hypothesis: individuals hospitalised for less than 15 days had significantly lower suicide risk than longer-stay patients. However, long-stay patients can also be prematurely discharged. In Paper I, in addition to the effect of 
length of stays, we studied the possible period effect of a trend towards shorter stays for both short and long-stay patients.

In the studies that related the increased risk of suicide among patients with psychiatric disorders to the reform labelled 'deinstitutionalisation', no statistical tests were computed [7379]. Thus, based on these studies, there is actually no convincing evidence that the observed increase in suicides was due to this psychiatric reform.

Based on Finish nationwide registers, Pirkola and co-workers [117] reported results in line with findings in our study. They studied suicide risk among psychiatric hospitalised patients immediately after discharge and one year after in the time periods 1985-1991 and 1995-2001. Because of the move towards shorter hospital stays, and thereby increased risk of premature discharges, they expected to find a greater suicide risk in the latter period. However, they found a cohort effect of greater suicide risk immediately $($ Risk ratio $=1.50 ; 95 \% \mathrm{CI}=1.38$ $1.62)$ and one year after discharge $(R R=1.25 ; 95 \% C I=1.19-1.30)$ in the former period. They concluded by stating that restructuring and downsizing of traditional mental health services were associated with decreased risk of post-discharge suicides. Further, in another Finish study that addressed the downsizing of hospitals in favour of community mental health services, it was documented that well-developed community mental health services were associated with lower suicide risk than services oriented towards inpatient treatment provision [119].

\section{Paper II}

In line with the results in Paper I and results reported by Pirkola and co-workers [117], fewer hospital beds and shortened length of stays were not associated with increased suicide 
mortality. Our main finding in Paper II was that substantial changes towards increased resources in Norwegian mental health services were unrelated to female and male suicide mortality over the period 1990-2006. This finding is in line with a recently published crossnational ecological study [85]. This study showed no relation between suicide rates and mental health funding, service provision and national policies on mental health. Further, in an ecological study from the United Kingdom, Lewis and co-workers [83] examined the association between suicide standardized mortality ratios and the provision of mental health services. The results showed that a higher quantity of provision was not negatively associated with suicide standardized mortality ratios. In addition, our findings are in line with a prospective multi-level study from the United States [120]. The researcher found no association between the variation in patterns of service delivery at the system level and the risk of suicide. However, there are ecological studies that have reported associations between various measurements of mental health service provisions and suicide rates $[80,81,119]$, e.g. Kapusta and co-workers found that both sales of antidepressants and density of psychotherapists were negatively associated with suicide rates. Hence, studies that have addressed suicide risk in relation to mental health services show contradictory results. It is therefore difficult to draw any firm conclusions.

\section{Paper III}

In line with the results in Paper III, other studies have indicated the effects of interventions that practice active outreach and contact maintenance on a regular basis after a person attempts suicide [98, 101, 103, 107]. In a quasi experimental study, Hvid and Wang [107] tested an outreach intervention similar to the chain of care model in Bærum. They found that individuals in the intervention group, who were offered follow-up care by a rapid response outreach program, had a lower rate of repeated suicide attempts than the control group $(\mathrm{RR}=$ 
$0.43 ; 95 \% \mathrm{CI}=0.23-0.80$ ). However, it is not yet documented in a randomised controlled trial if this kind of intervention is effective in preventing suicide [106].

\subsection{Conclusions}

We found that quite extensive changes in mental health services were unrelated to suicidal behaviour. Contrary to what was expected, the process of downsizing psychiatric hospitals and consequently shortened length of stays did not lead to an increased risk of subsequent suicidal behaviour among inpatient suicide attempters. Considering that shortened length of stays may increase the likelihood of premature discharges and incomplete recovery, we concluded that it was possible that shortened length of stays were compensated by increased resources in mental health services in general and development of outpatient services in particular.

Inspired by the results above, we anticipated that quantitative improvements in Norwegian mental health services might have had a preventive impact on suicide mortality at the societal level. In line with results from the first study, fewer beds and shortened length of stays were unrelated to suicide mortality. However, the total increase in mental health service resources and an increased number of individuals receiving treatment were not significantly associated with decreased suicide mortality either.

Hence, our results indicate that the process of decentralisation and downsizing of psychiatric hospitals has not had any negative consequences for suicidal behaviour. On the other hand, we cannot conclude that the substantial increase in mental health service resources had a preventive impact on suicide mortality. 
The study addressing the chain of care intervention for patients who had attempted suicide revealed promising results. Those requiring more help at time of the suicide attempt were indistinguishable, in terms of outcomes, after the intervention, from those not initially requiring the intervention. However, we cannot determine this effectiveness with certainty. The present study allows for selection bias.

\section{References}

1. Silverman MM, Felner RD: The place of suicide prevention in the spectrum of intervention: definitions of critical terms and constructs. Suicide Life Threat Behav 1995, 25:70-81.

2. Silverman MM, Berman AL, Sanddal ND, O'Carroll PW, Joiner TE: Rebuilding the tower of Babel: a revised nomenclature for the study of suicide and suicidal behaviors. Part 1: Background, rationale, and methodology. Suicide Life Threat Behav 2007, 37:248-63.

3. Silverman MM, Berman AL, Sanddal ND, O'Carroll PW, Joiner TE: Rebuilding the tower of Babel: a revised nomenclature for the study of suicide and suicidal behaviors. Part 2: Suicide-related ideations, communications, and behaviors. Suicide Life Threat Behav 2007, 37:264-77.

4. De Leo D, Burgis S, Bertolote JM, Kerkhof AJ, Bille-Brahe U: Definitions of suicidal behavior: lessons learned from the WHO/EURO multicentre Study. Crisis 2006, 27:4-15.

5. Linehan MM: Behavioral treatments of suicidal behaviors. Definitional obfuscation and treatment outcomes. Ann N Y Acad Sci 1997, 836:302-28.

6. Rudd MD: What's in a name.. Suicide Life Threat Behav 1997, 27:326-7.

7. O'Carroll PW, Berman AL, Maris RW, Moscicki EK, Tanney BL, Silverman MM: Beyond the Tower of Babel: a nomenclature for suicidology. Suicide Life Threat Behav 1996, 26:237-52. 
8. Owens D, Horrocks J, House A: Fatal and non-fatal repetition of self-harm Systematic review. Br J Psychiatry 2002, 181:193-9.

9. Hawton K, Fagg J, Simkin S, Bale E, Bond A: Trends in deliberate self-harm in Oxford, 1985-1995 - Implications for clinical services and the prevention of suicide. Br J Psychiatry 1997, 171:556-60.

10. van der Sande R, van Rooijen L, Buskens E, Allart E, Hawton K, van der Graaf Y, et al.: Intensive in-patient and community intervention versus routine care after attempted suicide. A randomised controlled intervention study. Br J Psychiatry 1997, 171:35-41.

11. Skegg K: Self-harm. Lancet 2005, 366:1471-83.

12. Moscicki EK: Epidemiology of completed and attempted suicide: toward a framework for prevention. Clinical Neuroscience Research 2001, 1:310-23.

13. Moscicki EK: Epidemiology of suicidal behavior. Suicide Life Threat Behav 1995, 25:22-35.

14. Beautrais AL: Suicides and serious suicide attempts: two populations or one? Psychol Med 2001, 31:837-45.

15. Platt S, Bille Brahe U, Kerkhof A, Schmidtke A, Bjerke T, Crepet P, et al.:

Parasuicide in Europe - the Who Euro Multicenter Study on Parasuicide .1. Introduction and Preliminary-Analysis for 1989. Acta Psychiatr Scand 1992, 85:97-104.

16. World Health Organization: World report on violence and health. Geneva; 2002.

17. World Health Organization: World health statistics. Geneva; 1989.

18. World Health Organization: Guidelines for the primary prevention of mental, neurological and psychosocial disorders. 4. Suicide [http://whqlibdoc.who.int/hq/1993/WHO_MNH_MND_93.24.pdf] (Retrieved 12.12.2010).

19. Hawton K, van Heeringen K: Suicide. Lancet 2009, 373:1372-81. 
20. Statistics Norway: Deaths, by sex and diagnoses classified in groups. (Based on European shortlist)

[http://statbank.ssb.no/statistikkbanken/Default_FR.asp?Productid $=03.01 \&$ PXSid $=0 \&$ nvl=true $\&$ PLanguage $=1 \&$ tilside $=$ selecttable $/$ MenuSelP. asp $\&$ SubjectCode $=03$ ] (Retrieved 12.12.2010).

21. Kessler RC, Borges G, Walters EE: Prevalence of and risk factors for lifetime suicide attempts in the National Comorbidity Survey. Arch Gen Psychiatry 1999, 56:617-26.

22. De Leo D, Cerin E, Spathonis K, Burgis S: Lifetime risk of suicide ideation and attempts in an Australian community: prevalence, suicidal process, and helpseeking behaviour. $J$ Affect Disord 2005, 86:215-24.

23. Leon AC, Friedman RA, Sweeney JA, Brown RP, Mann JJ: Statistical issues in the identification of risk factors for suicidal behavior: the application of survival analysis. Psychiatry Res 1990, 31:99-108.

24. Mann JJ, Waternaux C, Haas GL, Malone KM: Toward a clinical model of suicidal behavior in psychiatric patients. Am J Psychiatry 1999, 156:181-9.

25. Cavanagh JT, Carson AJ, Sharpe M, Lawrie SM: Psychological autopsy studies of suicide: a systematic review. Psychol Med 2003, 33:395-405.

26. Harris EC, Barraclough B: Suicide as an outcome for mental disorders - A metaanalysis. Br J Psychiatry 1997, 170:205-28.

27. Cooper J, Kapur N, Webb R, Lawlor M, Guthrie E, Mackway-Jones K, et al.: Suicide after deliberate self-harm: a 4-year cohort study. Am J Psychiatry 2005, 162:297303.

28. Suominen K, Isometsa E, Suokas J, Haukka J, Achte K, Lonnqvist J: Completed suicide after a suicide attempt: A 37-year follow-up study. Am J Psychiatry 2004, 161:562-3.

29. Ostamo A, Lonnqvist J: Excess mortality of suicide attempters. Soc Psychiatry Psychiatr Epidemiol 2001, 36:29-35. 
30. De Leo D: Struggling against suicide: the need for an integrative approach. Crisis 2002, 23:23-31.

31. Eckersley R, Dear K: Cultural correlates of youth suicide. Social Science \& Medicine 2002, 55:1891-904.

32. Pritchard C: Suicide in the People's Republic of China categorized by age and gender: evidence of the influence of culture on suicide. Acta Psychiatr Scand 1996, 93:362-7.

33. Stack S: Suicide: a 15-year review of the sociological literature. Part II: modernization and social integration perspectives. Suicide Life Threat Behav 2000, 30:163-76.

34. Stack S: Suicide: a 15-year review of the sociological literature. Part I: cultural and economic factors. Suicide Life Threat Behav 2000, 30:145-62.

35. Qin P, Agerbo E, Mortensen PB: Suicide risk in relation to socioeconomic, demographic, psychiatric, and familial factors: A national register-based study of all suicides in Denmark, 1981-1997. Am J Psychiatry 2003, 160:765-72.

36. Johansson SE, Sundquist $\mathrm{J}$ : Unemployment is an important risk factor for suicide in contemporary Sweden: an 11-year follow-up study of a cross-sectional sample of 37,789 people. Public Health 1997, 111:41-5.

37. Strand BH, Kunst A: Childhood socioeconomic position and cause-specific mortality in early adulthood. Am J Epidemiol 2007, 165:85-93.

38. Burrows S, Auger N, Roy M, Alix C: Socio-economic inequalities in suicide attempts and suicide mortality in Quebec, Canada, 1990-2005. Public Health 2010, 124:78-85.

39. Leenaars AA: Suicide: a multidimensional malaise. Suicide Life Threat Behav 1996, 26:221-36.

40. O'Connor RC, Noyce R: Personality and cognitive processes: Self-criticism and different types of rumination as predictors of suicidal ideation. Behaviour Research and Therapy 2008, 46:392-401. 
41. Rasmussen SA, Fraser L, Gotz M, MacHale S, Mackie R, Masterton G, et al.: Elaborating the cry of pain model of suicidality: Testing a psychological model in a sample of first-time and repeat self-harm patients. British Journal of Clinical Psychology 2010, 49:15-30.

42. Baumeister RF: Suicide as escape from self. Psychol Rev 1990, 97:90-113.

43. Purselle DC, Nemeroff CB: Serotonin transporter: a potential substrate in the biology of suicide. Neuropsychopharmacology 2003, 28:613-9.

44. Oquendo MA, Mann JJ: The biology of impulsivity and suicidality. Psychiatr Clin North Am 2000, 23:11-25.

45. Mann JJ: Neurobiology of suicidal behaviour. Nat Rev Neurosci 2003, 4:819-28.

46. Mortensen PB, Agerbo E, Erikson T, Qin P, Westergaard-Nielsen N: Psychiatric illness and risk factors for suicide in Denmark. Lancet 2000, 355:9-12.

47. Qin $\mathrm{P}$, Nordentoft $\mathrm{M}$ : Suicide risk in relation to psychiatric hospitalization: evidence based on longitudinal registers. Arch Gen Psychiatry 2005, 62:427-32.

48. Bramness JG, Walby FA, Hjellvik V, Selmer R, Tverdal A: Self-reported mental health and its gender differences as a predictor of suicide in the middle-aged. $\mathrm{Am}$ J Epidemiol 2010, 172:160-6.

49. Suominen K, Henriksson M, Suokas J, Isometsa E, Ostamo A, Lonnqvist J: Mental disorders and comorbidity in attempted suicide. Acta Psychiatr Scand 1996, 94:234-40.

50. Haw C, Hawton K, Houston K, Townsend E: Psychiatric and personality disorders in deliberate self-harm patients. Br J Psychiatry 2001, 178:48-54.

51. Henriksson MM, Aro HM, Marttunen MJ, Heikkinen ME, Isometsa ET, Kuoppasalmi KI, et al.: Mental disorders and comorbidity in suicide. Am J Psychiatry 1993, 150:935-40.

52. Isometsa ET: Psychological autopsy studies--a review. Eur Psychiatry 2001, 16:379-85. 
53. Hawton K, Appleby L, Platt S, Foster T, Cooper J, Malmberg A, et al.: The psychological autopsy approach to studying suicide: a review of methodological issues. $J$ Affect Disord 1998, 50:269-76.

54. Brent DA, Perper JA, Moritz G, Allman C, Friend A, Roth C, et al.: Psychiatric risk factors for adolescent suicide: a case-control study. J Am Acad Child Adolesc Psychiatry 1993, 32:521-9.

55. Lesage AD, Boyer R, Grunberg F, Vanier C, Morissette R, Menard-Buteau C, et al.: Suicide and mental disorders: a case-control study of young men. Am J Psychiatry 1994, 151:1063-8.

56. Shaffer D, Gould MS, Fisher P, Trautman P, Moreau D, Kleinman M, et al.:

Psychiatric diagnosis in child and adolescent suicide. Arch Gen Psychiatry 1996, 53:339-48.

57. Shafii M, Steltz-Lenarsky J, Derrick AM, Beckner C, Whittinghill JR: Comorbidity of mental disorders in the post-mortem diagnosis of completed suicide in children and adolescents. $J$ Affect Disord 1988, 15:227-33.

58. Appleby L, Cooper J, Amos T, Faragher B: Psychological autopsy study of suicides by people aged under 35. Br J Psychiatry 1999, 175:168-74.

59. Foster T, Gillespie K, McClelland R, Patterson C: Risk factors for suicide independent of DSM-III-R Axis I disorder. Case-control psychological autopsy study in Northern Ireland. Br J Psychiatry 1999, 175:175-9.

60. Vijayakumar L, Rajkumar S: Are risk factors for suicide universal? A case-control study in India. Acta Psychiatr Scand 1999, 99:407-11.

61. Blair-West GW, Cantor CH, Mellsop GW, Eyeson-Annan ML: Lifetime suicide risk in major depression: sex and age determinants. $J$ Affect Disord 1999, 55:171-8.

62. Kringlen E, Torgersen S, Cramer V: A Norwegian psychiatric epidemiological study. Am J Psychiatry 2001, 158:1091-8. 
63. Meehan J, Kapur N, Hunt IM, Turnbull P, Robinson J, Bickley H, et al.: Suicide in mental health in-patients and within 3 months of discharge. National clinical survey. Br J Psychiatry 2006, 188:129-34.

64. Goldacre M, Seagroatt V, Hawton K: Suicide After-Discharge from Psychiatric Inpatient Care. Lancet 1993, 342:283-6.

65. Kan CK, Ho TP, Dong JYS, Dunn ELW: Risk factors for suicide in the immediate post-discharge period. Social Psychiatry and Psychiatric Epidemiology 2007, 42:208-14.

66. Beautrais AL, Joyce PR, Mulder RT, Fergusson DM, Deavoll BJ, Nightingale SK: Prevalence and comorbidity of mental disorders in persons making serious suicide attempts: a case-control study. Am J Psychiatry 1996, 153:1009-14.

67. Lewinsohn PM, Rohde P, Seeley JR: Adolescent suicidal ideation and attempts: Prevalence, risk factors, and clinical implications. Clinical Psychology-Science and Practice 1996, 3:25-46.

68. Coughlin SS, Benichou J, Weed DL: Attributable risk estimation in case-control studies. Epidemiol Rev 1994, 16:51-64.

69. Gjertsen F, Nesje I, Espeland B, Haddeland AL, Reinholdt NP, Stokkvik EH: Variation in suicide mortality across regions in Norway 1996-2006. [In press].

70. Rothman KJ: Epidemiology. An Introduction. Oxford, Oxford University Press; 2002

71. Pedersen PB, Kolstad A: De-institutionalisation and trans-institutionalisation changing trends of inpatient care in Norwegian mental health institutions 19502007. Int J Ment Health Syst 2009, 3:28.

72. Lamb HR, Bachrach LL: Some perspectives on deinstitutionalization. Psychiatric Services 2001, 52:1039-45.

73. Currier GW: Psychiatric bed reductions and mortality among persons with mental disorders. Psychiatric Services 2000, 51:851.

74. Goldney RD: Deinstitutionalization and suicide. Crisis 2003, 24:39-40. 
75. Hansen V, Jacobsen BK, Arnesen E: Cause-specific mortality in psychiatric patients after deinstitutionalisation. Br J Psychiatry 2001, 179:438-43.

76. Mortensen PB, Juel K: Mortality and causes of death in first admitted schizophrenic patients. Br J Psychiatry 1993, 163:183-9.

77. Munk-Jørgensen P: Has deinstitutionalization gone too far? Eur Arch Psychiatry Clin Neurosci 1999, 249:136-43.

78. Salokangas RK, Honkonen T, Stengard E, Koivisto AM: Mortality in chronic schizophrenia during decreasing number of psychiatric beds in Finland. Schizophr Res 2002, 54:265-75.

79. Bassett D, Tsourtos G: Inpatient Suicide in A General-Hospital Psychiatric Unit A Consequence of Inadequate Resources. Gen Hosp Psychiatry 1993, 15:301-6.

80. Kapusta ND, Niederkrotenthaler T, Etzersdorfer E, Voracek M, Dervic K, Jandl-Jager E, et al.: Influence of psychotherapist density and antidepressant sales on suicide rates. Acta Psychiatr Scand 2009, 119:236-42.

81. Tondo L, Albert MJ, Baldessarini RJ: Suicide rates in relation to health care access in the United States: an ecological study. J Clin Psychiatry 2006, 67:517-23.

82. Korkeila J, Salminen JK, Hiekkanen H, Salokangas RK: Use of antidepressants and suicide rate in Finland: an ecological study. J Clin Psychiatry 2007, 68:505-11.

83. Lewis G, Appleby L, Jarman B: Suicide and psychiatric services. Lancet 1994, 344:822.

84. Appleby L, Dennehy JA, Thomas CS, Faragher EB, Lewis G: Aftercare and clinical characteristics of people with mental illness who commit suicide: a case-control study. Lancet 1999, 353:1397-400.

85. Shah A, Bhandarkar R, Bhatia G: The relationship between general population suicide rates and mental health funding, service provision and national policy: a cross-national study. Int J Soc Psychiatry 2010, 56:448-53. 
86. Norwegian board of health: Mental health services in Norway

[http://www.regjeringen.no/upload/kilde/hod/red/2005/0011/ddd/pdfv/233840mentalhealthweb.pdf] (Retrieved 12.12.2010)

87. Vold B: Psykiatrien på 1990-tallet: Mer aktiv behandling [Psychiatric Services in the 90s: More Integrative Treatment]. Oslo: Helse og omsorgstjenester, Statistiske analyser 56, Statistics Norway; 2002.

88. Statistics Norway: Psychiatric institutions for adults. Beds, discharges, bed-days, out-patient consultations and day cases.

[http://statbank.ssb.no/statistikkbanken/Default_FR.asp?PXSid=0\&nvl=true\&PLangu age $=1 \&$ tilside $=$ selecttable/hovedtabellHjem.asp\&KortnavnWeb $=$ speshelsepsyk $]$ (Retrieved 12.12.2010).

89. Ministry of Health and Care Services: St meld $n r 25$ (1996-1997) åpenhet og helhet.Om psykiske lidelser og tjenestetilbudene [Psychiatric Disorders and Health Services]. Oslo; 1997.

90. Ministry of Health and Care Services: St prop $n r 63$ (1999-2008) Opptrappingsplanen for psykisk helse 1999-2006. Oslo; 1998.

91. Brofoss K, Larsen F: Evaluering av opptrappingsplanen for psykisk helse (20012009). Sluttrapport - syntese og analyse av evalueringens delprosjekter. Oslo, Norges forskningsråd [The Norwegian research Council); 2009.

92. Norwegian Board of Health: The national plan for suicide prevention 1994-1998. Skriftserie 1996: 2 IK-2539. Oslo; 1996.

93. Hawton K, Arensman E, Townsend E, Bremner S, Feldman E, Goldney R, et al.: Deliberate self harm: systematic review of efficacy of psychosocial and pharmacological treatments in preventing repetition. Br Med $J$ 1998, 317:441-7.

94. Gunnell D, Frankel S: Prevention of suicide: aspirations and evidence. BMJ 1994, 308:1227-33.

95. Gibbons JS, Butler J, Urwin P, Gibbons JL: Evaluation of a social work service for self-poisoning patients. Br J Psychiatry 1978, 133:111-8. 
96. Hawton K, McKeown S, Day A, Martin P, O'Connor M, Yule J: Evaluation of outpatient counselling compared with general practitioner care following overdoses. Psychol Med 1987, 17:751-61.

97. McLeavey BC, Daly RJ, Ludgate JW, Murray CM: Interpersonal problem-solving skills training in the treatment of self-poisoning patients. Suicide Life Threat Behav 1994, 24:382-94.

98. Salkovskis PM, Atha C, Storer D: Cognitive-behavioural problem solving in the treatment of patients who repeatedly attempt suicide. A controlled trial. $\mathrm{Br} J$ Psychiatry 1990, 157:871-6.

99. Linehan MM, Armstrong HE, Suarez A, Allmon D, Heard HL: Cognitive-behavioral treatment of chronically parasuicidal borderline patients. Arch Gen Psychiatry 1991, 48:1060-4.

100. Hepp U, Wittmann L, Schnyder U, Michel K: Psychological and psychosocial interventions after attempted suicide: an overview of treatment studies. Crisis 2004, 25:108-17.

101. Guthrie E, Kapur N, Mackway-Jones K, Chew-Graham C, Moorey J, Mendel E, et al.: Randomised controlled trial of brief psychological intervention after deliberate self poisoning. $B M J 2001, \mathbf{3 2 3}: 135-8$.

102. Bateman A, Fonagy P: Effectiveness of partial hospitalization in the treatment of borderline personality disorder: a randomized controlled trial. Am J Psychiatry 1999, 156:1563-9.

103. Welu TC: A follow-up program for suicide attempters: evaluation of effectiveness. Suicide Life Threat Behav 1977, 7:17-20.

104. Mann JJ, Apter A, Bertolote J, Beautrais A, Currier D, Haas A, et al.: Suicide prevention strategies: a systematic review. JAMA 2005, 294:2064-74.

105. Rodgers PL, Sudak HS, Silverman MM, Litts DA: Evidence-based practices project for suicide prevention. Suicide Life Threat Behav 2007, 37:154-64. 
106. Norwegian Knowledge Centre for the Health Services: Prevention of suicide Part II. [http://www.kunnskapssenteret.no/Publikasjoner/678.cms?language=english]. (Retrieved 12.12.2010).

107. Hvid M, Wang AG: Preventing repetition of attempted suicide--I. Feasibility (acceptability, adherence, and effectiveness) of a Baerum-model like aftercare. Nord J Psychiatry 2009, 63:148-53.

108. Norwegian Board of Health: The Bcerum model 1984-1994. skriftserie 1-98. Oslo; 1995.

109. Shneidman E: Definition of Suicide. New York, John Wiley \& Sons; 1985

110. Dieserud G, Loeb M, Ekeberg O: Suicidal behavior in the municipality of Baerum, Norway: A 12-year prospective study of parasuicide and suicide. Suicide Life Threat Behav 2000, 30:61-73.

111. Sirus RusStat - rusmiddelstatistikk på nett [http://statistikk.sirus.no/sirus/] (Retrieved 12.12.2010).

112. NorPD: definitions [http://www.norpd.no/] (Retrieved 12.12.2010).

113. Statistics Norway [http://www.ssb.no/vis/speshelse/om.html] (Retrieved 12.12.2010).

114. Kuhn L, Davidson LL, Durkin MS: Use of Poisson regression and time series analysis for detecting changes over time in rates of child injury following a prevention program. Am J Epidemiol 1994, 140:943-55.

115. Schwartz S: The fallacy of the ecological fallacy: the potential misuse of a concept and the consequences. Am J Public Health 1994, 84:819-24.

116. Ho TP: Duration of hospitalization and post discharge suicide. Suicide Life Threat Behav 2006, 36:682-6.

117. Pirkola S, Sohlman B, Heila H, Wahlbeck K: Reductions in Postdischarge Suicide After Deinstitutionalization and Decentralization: A Nationwide Register Study in Finland. Psychiatr Serv 2007, 58:221-6. 
118. Qin $\mathrm{P}$, Nordentoft $\mathrm{M}$ : Suicide risk in relation to psychiatric hospitalization: evidence based on longitudinal registers. Arch Gen Psychiatry 2005, 62:427-32.

119. Pirkola S, Sund R, Sailas E, Wahlbeck K: Community mental-health services and suicide rate in Finland: a nationwide small-area analysis. Lancet 2009, 373:14753.

120. Desai RA, Dausey DJ, Rosenheck RA: Mental health service delivery and suicide risk: The role of individual patient and facility factors. Am J Psychiatry 2005, 162:311-8. 

I 



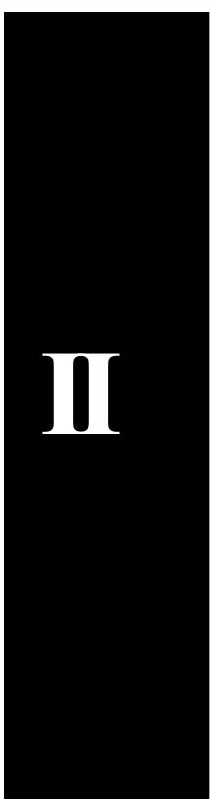





\section{Changes in mental health services and suicide mortality in Norway: an ecological study}

Håkon A. Johannessen ${ }^{1 \S}$, Gudrun Dieserud ${ }^{1}$, Bjørgulf Claussen ${ }^{2}$ and Per-

Henrik Zahl ${ }^{1}$

Address: ${ }^{1}$ Division of Mental Health, Department of Suicide Research and

Prevention, Norwegian Institute of Public Health, Oslo, Norway

${ }^{2}$ Institute of General Practice and Community Health, Section for Social

Medicine, University of Oslo, Oslo, Norway

${ }^{\S}$ Corresponding author

Email:

HAJ: hajn@fhi.no

GD: gudrun.dieserud@,fhi.no

BC: bjorgulf.claussen@medisin.uio.no

PHZ: per-henrik.zahl@,fhi.no 


\section{Abstract}

\section{Background}

Mental disorders are strongly associated with excess suicide risk, and successful treatment might prevent suicide. Since 1990, and particularly after 1998, there has been a substantial increase in mental health service resources in Norway. This study aimed to investigate if these changes have had an impact on suicide mortality.

\section{Methods}

We used Poisson regression analyses to assess the effect of changes in five mental health services variables on suicide mortality in five Norwegian health regions during the period 1990-2006. These variables included: number of man-labour years by all personnel, number of discharges, number of outpatient consultations, number of inpatient days, and number of hospital beds. Adjustments were made for sales of alcohol, sales of antidepressants, education and unemployment.

\section{Results}

In the period 1990-2006, we observed a total of 9480 suicides and the total suicide rate declined by $26 \%$. None of the mental health services variables were significantly associated with female or male suicide mortality in the adjusted analyses $(\mathrm{P}>0.05)$. Sales of antidepressants (adjusted Incidence Rate Ratio $=0.98 ; 95 \%$ CI $=0.97-1.00$ ) and sales of alcohol (adjusted $\mathrm{IRR}=1.41 ; 95 \% \mathrm{CI}=1.18-1.72$ ) were significantly associated with female suicide mortality; whereas education (adjusted $\mathrm{IRR}=0.86$; $95 \% \mathrm{CI}=0.79-0.94)$ and unemployment (adjusted $\mathrm{IRR}=0.91 ; 95 \% \mathrm{CI}=0.85-0.97)$ were significantly associated with male suicide mortality. 


\section{Conclusions}

The adjusted analyses in the present study indicated that increased resources in Norwegian mental health services in the period 1990-2006 were statistically unrelated to suicide mortality. 


\section{Background}

Suicide is a complex behavioural phenomenon in which cultural, social and psychological aspects play important roles $[1,2]$. Thus, suicide can not be reduced to a disease $[3,4]$. Still, it is well documented that several mental disorders increase the likelihood of suicide $[5,6]$, e.g. statistics from Norway show that about $15 \%$ of all who commit suicide were at the time of death in specialist mental health treatment for a psychiatric disorder [7]. Treatment of mental disorders has therefore become a key element in suicide prevention efforts, as reflected in both international guidelines from the World Health Organization [8] and several national suicide prevention programs, including the Norwegian national plan (1994) [9].

In the Norwegian democratic welfare state, public authorities are responsible for providing and financing health services [10]. The municipalities have responsibility for the provision of primary health services and the central government has the responsibility for the provision of specialised health services. All Norwegian citizens have, by law, the right to necessary and adequate health treatment and care [10].

As in most industrialised countries, mental health services in Norway have been deinstitutionalised and decentralised in recent decades $[11,12]$. This process entailed a shift in primary focus from inpatient to outpatient care, grounded in the assumption that decentralised and community-based mental health services would be more caring, integrative, and therapeutically successful than the traditional state hospital care [13]. Likewise, in the field of clinical suicidology, the paradigm of the hospital as a necessary part of safeguarding suicidal individuals has been increasingly 
questioned [14]. Researchers from Finland reported a reduced suicide risk among psychiatric patients after the period of mental health deinstitutionalization [15]. It has also been reported from Finland that municipalities with primarily outpatient and community-based mental health care were associated with lower suicide rates than municipalities with services primarily oriented towards inpatient treatment provision [16].

Not only were the mental health services in Norway deinstitutionalised, but also the resources for mental health services were considerably strengthened in quantitative terms in the period 1990-2006. Additionally, in 1998 the Norwegian Parliament adopted a national program calling for major investments in mental health services, to be implemented starting in 1999, with targets to be fully reached by the end of 2008 [17]. The expenditures in specialist mental health services had a real growth of $175 \%$ from 1998-2007 [18]. In general, the investments in adult psychiatric care were allocated to increase the number of health personnel with college and university education. Further, to build more decentralised psychiatric centres and to increase the quantity and quality of inpatient and outpatient care in these centres [18]. Evaluation studies have documented that the National program has had a positive impact on patients' access to mental health services $[12,18,19]$.

Recently, in two ecological studies from the United States and Austria, it was reported that the accessibility of mental health services [20] and the density of psychotherapists [21] were negatively associated with suicide rates. These findings need to be replicated. In Norway, no studies have addressed whether increased 
investments in mental health services over the last two decades have impacted the suicide rate.

The aim of this study was to determine if increased mental health service resources had an impact on suicide mortality in five Norwegian health regions in the period 1990-2006.

\section{Methods}

All data used in the present study are openly available and can be downloaded at Statistics Norway and Norwegian Institute for Alcohol and Drug Research, except data on sales of antidepressants which can be provided by the Wholesales register in Norway by request.

In the period 1990-2006, specialist health services in Norway were organised in five health regions. Data on suicide rates in the health regions was provided by the Causes-of-Death Registry at Statistics Norway [22]. This registry has an almost complete registration of causes of death. In the period 1986-1995, causes of deaths were classified according to the International Classification of Diseases Ninth Revision (ICD-9) and from 1996 onwards according to the ICD-10.

To measure changes in mental health services, we used available health service variables provided by Statistics Norway [23]: these were the number of beds per 1000 inhabitants (beds); the number of inpatient-days per 1000 inhabitants (bed-days); the number of discharges per 1000 inhabitants (discharges); the number of outpatient consultations per 1000 inhabitants (outpatient consultations); and the number of man- 
labour years by all personnel in mental health services per 1000 inhabitants. Regional figures were available from 1998 onwards. For the period before 1998, annual national figures were used.

The number of inpatient-days is calculated by subtracting the patient's date of discharge from the date of hospital admittance, that is, the number of days a patient remains in hospital [24]. The number of beds is a calculation of accessible beds in the institutions as of 31 December each year [24]. In contrast to bed-days, the number of beds is a measure of the institutions' treatment capacity [24]. The number of discharges is administrative episodes, that is, the same patient can be discharged more than once in a year [24]. Outpatient consultations "include consultations carried out in outpatient clinics or in psychiatric institutions, giving reimbursement from the state" [24]. The total number of man-labour years is estimated as: "the number of full-time jobs and part-time jobs calculated as full-time equivalents adjusted for doctorcertified sickness absence and maternity leave" [24].

To adjust for competing explanatory variables, we used regional data on education and unemployment; and national data on sales of alcohol and sales of antidepressants, all of which have been reported to be associated with suicide mortality [25-28]. In addition, we analysed for linear trends in the period 1990-2006.

Sales of pure alcohol in litres per inhabitant above the age of 15 for the whole country were provided by the Norwegian Institute for Alcohol and Drug Research [29]. The figure of alcohol sales for the year 1998 was missing. The figure for this year was imputed as the average of the figures in 1997 and 1999. 
Sales of antidepressants were provided by the Wholesales register in Norway. These data represent total sales to pharmacies and institutions. In Norway, drugs are grouped according to the Anatomical Therapeutic Chemical (ATC) classification [30]. The total national sales of ATC group N06A (antidepressants) was recorded, and the sales numbers were standardised as defined daily doses (DDD)/1000 inhabitants/day for the period 1990-2006. Sales figures of antidepressants are a proxy measure, we do not know if these drugs are consumed by patients.

Annual regional figures of the proportion of men and women per 100 with college or university education [31], and annual regional figures of the proportion of men and women per 100 unemployed [32] were provided by Statistics Norway.

A power computation showed an $80 \%$ probability of detecting a reduction in the total suicide rate of $8 \%$ or more at a $5 \%$ significance level. Data were analysed by computing crude rates and Poisson regression. Separate analyses were computed for males and females. We tested each Poisson model for over-dispersion by comparing the deviance with its degrees of freedom. The deviance is a measure of the discrepancy between observed and fitted values [33]. By comparing the deviance with its degrees of freedom, a goodness of fit measure is provided [33]. If the goodness of fit test is significant the model is inappropriate [33].

We substituted missing regional date with average national data. To examine if this procedure had unwanted bearings on the results, we fitted national models with complete data and compared the results with the regional models. In addition, to rule 
out the possibility of a collinearity problem, we also computed an adjusted model in which each health services variable was analysed separately.

\section{Results}

From 1990 to 2006, the total suicide rate in Norway decreased by 26\% (Table 1 and Figure 1). In the same period, the number of man-labour years by all personnel, the number of discharges, and the number of outpatient consultations increased by $16 \%$, $113 \%$, and $221 \%$, respectively, whereas the number of psychiatric hospital beds and inpatient-days declined by $42 \%$ and $43 \%$, respectively (Table 1). Sales of antidepressants (defined daily doses (DDD)/1000 inhabitants/day) and alcohol (pure alcohol in liters per inhabitant above the age of 15 ) increased by $353 \%$ and $29 \%$, respectively (Table 1). The proportion of unemployed individuals declined by $33 \%$ in this period; whereas the proportion of individuals with college or university education increased by $60 \%$ (Table 1). Regional figures are shown in Table 2.

As Figure 1 shows, the suicide rate declined the most from 1990 to 1994 (crude annual Incidence Rate Ratio $=0.94 ; 95 \% \mathrm{CI}=0.91-0.97)$ and levelled off after that (crude annual IRR $=0.99 ; 95 \% \mathrm{CI}=0.98-1.00$ ). In contrast, the major changes in the health services variables were observed in the years 2000-2006 (Table 1).

A total of 9480 suicides distributed over the five health regions in Norway were observed during the period 1990-2006. As Tables 3 and 4 show, all of the variables that measured resources in specialist mental health services were unrelated to male and female suicide mortality when adjusted for competing explanatory factors (adjusted $\mathrm{P}>0.05)$. 
Among women, the variables that best explained the variation in suicide mortality were health region, sales of alcohol (adjusted $\mathrm{P}=0.01$ ) and sales of antidepressants (adjusted $\mathrm{P}=0.03)$ (Table 3$)$. The highest suicide mortality was observed in the health region 'East,' whereas health region 'Mid' (adjusted incidence rate ratio = $0.68 ; 95 \% \mathrm{CI}=0.60-0.78$ ) had the lowest suicide mortality. A one-unit (one litre pure alcohol per inhabitant per year) increase in sales of alcohol predicted a $41 \%$ increase in suicide mortality (adjusted $\mathrm{IRR}=1.41 ; 95 \% \mathrm{CI}=1.18-1.72$ ), and a one-unit (one defined daily doses/1000 inhabitants/day) increase in sales of antidepressants predicted a $2 \%$ decline in suicide mortality (adjusted $\mathrm{IRR}=0.98 ; 95 \% \mathrm{CI}=0.97$ 1.00). As can be seen by the test statistics in Table 3, the computed Poisson model had a good data fit $(\mathrm{P}=0.27)$.

Among men, the variables that best explained the variation in suicide mortality were health region, education (adjusted $\mathrm{P}=0.01$ ) and unemployment (adjusted $\mathrm{P}=0.01$ ) (Table 4). The highest suicide mortality was observed in the region 'East'; whereas health region 'North' (adjusted IRR $=0.33 ; 95 \% \mathrm{CI}=0.18-0.58$ ) had the lowest suicide mortality. A one unit (1\%) increase in the proportion of men with college or university education predicted a 14\% decline in suicide mortality (adjusted IRR = $0.86 ; 95 \% \mathrm{CI}=0.79-0.94)$, and a one unit $(1 \%)$ decline in the proportion unemployed men predicted a $9 \%$ decline in suicide mortality $($ adjusted $\mathrm{IRR}=0.91 ; 95 \% \mathrm{CI}=$ 0.85-0.97). As can be seen by the test statistics in Table 4, the computed Poisson model had a good data fit $(\mathrm{P}=0.40)$. 
To control for a potential collinearity problem, we computed an adjusted model in which each of the five health services variables separately were included (not shown). None of the health services variables were statistically related to female or male suicide mortality (adjusted $\mathrm{P}>0.05$ ). We also computed a model with complete national data (not shown). None of the five mental health services variables were statistically associated with reduced suicide mortality for men or women (adjusted P $>0.05)$.

\section{Discussion}

The aim of this study was to investigate whether increased mental health services resources had an impact on suicide mortality in the five Norwegian health regions in the period 1990-2006. Although substantial changes in mental health services resources were observed (Table 1), female and male suicide mortality were statistically unrelated to these changes (adjusted $\mathrm{P}>0.05$ ) (Tables 3 and 4).

Despite the observed decline in hospital beds, the number of discharges increased by $113 \%$ in the study period, which can be explained by the decline in the number of inpatient days. The additional increase in outpatient consultations and man-labour years by all personnel indicates that more patients were treated throughout the period. It can be argued that shortened length of stays increases the risk of incomplete recovery and may explain the excess suicide risk generally observed in the immediate post-discharge period [34]. However, the data in the present study did not indicate increased suicide risk due to reduction in inpatient days. 
Several of the adjustment variables were significantly associated with suicide mortality. Among females, increased sales of antidepressants were associated with a decline in suicide mortality (adjusted $\mathrm{P}=0.03$ ); whereas increased sales of alcohol were associated with an increase in suicide mortality (adjusted $\mathrm{P}=0.01$ ). Among males, increased level of college and university education were associated with a decline in suicide mortality (adjusted $\mathrm{P}=0.01$ ), whereas declined level of unemployment was associated with a decline in suicide mortality (adjusted $\mathrm{P}=0.01$ ). Crude differences in male and female suicide mortality were observed across the health regions. Among females theses differences do not alter in the adjusted analysis; whereas adjustments for educational level and the level of unemployment impact the regional differences among males. We do not know why these crude regional differences in female and male suicide mortality exist.

The present study should be interpreted with caution because statistical associations can be masked by the fact that we may have failed to adjust for relevant confounders. Another shortage in the present study was that we only had one variable that directly measured the increased resources in outpatient services. Due to the process of downsizing traditional psychiatric hospitals, present mental health services policy favours active outpatient treatment. Thus, the negative findings may be due to restricted measurements on outpatient mental health services. Further, the increased resources in child and adolescent mental health services, which were not addressed in this study, may pay off in suicide rates later on. Finally, it is important to be aware that associations at the individual level cannot be deduced from an ecological study design. 
Our findings are in line with a recently published cross-national ecological study [35]. This study showed no relation between suicide rates and mental health funding, service provision and national policies on mental health. Further, in an ecological study from the United Kingdom, Lewis and co-workers [36] examined the association between suicide standardized mortality ratios and the provision of mental health services. The results showed that higher quantity of provision was not negatively associated with suicide standardized mortality ratios. In addition, our findings are in line with a prospective multi-level study from the United States, in which the researcher found no association between variation in patterns of service delivery at the system level and suicide risk [37]. However, there are ecological studies that have reported associations between various measurements of mental health services provision and suicide rates $[16,20,21]$, e.g. Kapusta [21] and co-workers found that both sales of antidepressants and density of psychotherapists were negatively associated with suicide rates.

It is undisputable that the Norwegian mental health services have been strengthened in quantitative terms. However, little is known about the content of the treatment given and thus the quality and effectiveness of the treatment [18]. Hence, we do not know if more patients during this period were successfully treated. In addition, there has not been developed varied interdisciplinary outpatient services that are specialised in handling suicidal patients.

Far from all suicidal mental health patients are receiving treatments proven to have a suicide preventive effect. A recent health technology assessment (review of the literature) of the effects of mental health services interventions for the prevention of 
suicide found that few interventions were specifically tailored to reduce suicidality [38]. Most of the studies examined in the assessment evaluated the effect of treatment related to mental illness per se. Further: "the inclusion and exclusion criteria were not always well described and in a number of studies individuals with high suicide risk were not included" [30]. This strategy, according to which suicidality is conceptualized as a symptom of mental illness and prevention of suicide requires treatment of the underlying disease, has come under increasing criticism [14, 39, 40]. An alternative strategy has been proposed, namely, a focus on suicidality as the primary clinical target, in which suicidal behaviour and its causes are addressed directly $[14,39]$. In this approach, the individual is seen as primarily suicidal with various sub-symptoms of mental illness in need of treatment [14].

Because suicide is a multi-factorial phenomenon, it is also reasonable to infer that effective suicide prevention strategies need to be broader than the focus on treatment of mental disorders. For example, public health prevention strategies that have aimed at restricting suicide means [41-43], toning down media reports [44], and restricting alcohol [45] have been shown to be successful. Multidisciplinary approaches to suicide research and prevention are needed - that is, research teams with "a balanced composition between biologically and psychologically oriented investigators" [2], and there is a "need to evaluate also other concomitant factors such as socioeconomic, cultural, and religious aspects" [2].

A multidisciplinary approach does not preclude the priority of suicide prevention among psychiatric patients, who constitute a group at increased risk, but treatment ought to target suicidality more specifically. 


\section{Conclusions}

Mental disorders are strongly associated with increased suicide risk. Thus, successful treatment may prevent suicide, and a greater number of treated individuals may impact the suicide rate. In this study we observed a substantial increase in mental health services resources in Norway during the period 1990-2006. However, the adjusted analyses indicated that these changes were statistically unrelated to female and male suicide mortality.

\section{Competing interests}

The authors declare that they have no competing interests.

\section{Authors' contributions}

HAJ made substantial contributions to conception and design of the manuscript, drafted the manuscript, analyzed and interpreted the data, and critically revised the manuscript for important intellectual content. PHZ made substantial contributions to conception and design of the manuscript, analyzed and interpreted the data, and critically revised the manuscript for important intellectual content. GD made substantial contributions to conception and design of the manuscript, interpreted the data, and critically revised the manuscript for important intellectual content. BC made substantial contributions to conception and design of the manuscript, interpreted the data, and critically revised the manuscript for important intellectual content. All authors read and approved the final manuscript.

\section{Acknowledgements}

This study was funded by the Research Council of Norway. 


\section{References}

1. Nordentoft M: Prevention of suicide and attempted suicide in Denmark. Epidemiological studies of suicide and intervention studies in selected risk groups. Dan Med Bull 2007, 54:306-69.

2. De Leo D: Struggling against suicide: the need for an integrative approach. Crisis 2002, 23:23-31.

3. Silverman MM, Berman AL, Sanddal ND, O'carroll PW, Joiner TE: Rebuilding the tower of Babel: a revised nomenclature for the study of suicide and suicidal behaviors. Part 1: Background, rationale, and methodology. Suicide Life Threat Behav 2007, 37:248-63.

4. Silverman MM, Berman AL, Sanddal ND, O'carroll PW, Joiner TE: Rebuilding the tower of Babel: a revised nomenclature for the study of suicide and suicidal behaviors. Part 2: Suicide-related ideations, communications, and behaviors. Suicide Life Threat Behav 2007, 37:264-77.

5. Harris EC, Barraclough B: Suicide as an outcome for mental disorders - A meta-analysis. Br J Psychiatry 1997, 170:205-28.

6. Mortensen PB, Agerbo E, Erikson T, Qin P, Westergaard-Nielsen N:

Psychiatric illness and risk factors for suicide in Denmark. Lancet 2000, 355:9-12.

7. Gjertsen F, Nesje I, Espeland B, Haddeland AL, Reinholdt NP, Stokkvik EH: Variation in suicide mortality across regions in Norway 1996-2006. [In press]

8. World Health Organization: Guidelines for the primary prevention of mental, neurological and psychosocial disorders. 4. Suicide [http://whqlibdoc.who.int/hq/1993/WHO_MNH_MND_93.24.pdf] 
9. The national plan for suicide prevention 1994-1998

[http://www.helsetilsynet.no/upload/Publikasjoner/skriftserien/national_plan_sui cide_prevention_ik-2539.html]

10. Mental health services in Norway

[http://www.regjeringen.no/upload/kilde/hod/red/2005/0011/ddd/pdfv/233840mentalhealthweb.pdf]

11. Lamb HR, Bachrach LL: Some perspectives on deinstitutionalization.

Psychiatric Services 2001, 52:1039-45.

12. Pedersen PB, Kolstad A: De-institutionalisation and transinstitutionalisation - changing trends of inpatient care in Norwegian mental health institutions 1950-2007. Int J Ment Health Syst 2009, 3:28.

13. Ministry of Health and Care Services: St meld $n r 25$ (1996-1997) åpenhet og helhet.Om psykiske lidelser og tjenestetilbudene [Psychiatric Disorders and Health Services]. Oslo; 1997.

14. Jobes DA: Collaborating to prevent suicide: A clinical-research perspective. Suicide Life Threat Behav 2000, 30:8-17.

15. Pirkola S, Sohlman B, Heila H, Wahlbeck K: Reductions in Postdischarge Suicide After Deinstitutionalization and Decentralization: A Nationwide Register Study in Finland. Psychiatr Serv 2007, 58:221-6.

16. Pirkola S, Sund R, Sailas E, Wahlbeck K: Community mental-health services and suicide rate in Finland: a nationwide small-area analysis. Lancet 2009, 373:147-53.

17. Ministry of Health and Care Services: St prop $n r 63$ (1999-2008) Opptrappingsplanen for psykisk helse 1999-2006. Oslo; 1998.

18. Brofoss K, Larsen F: Evaluering av opptrappingsplanen for psykisk helse (2001-2009). Sluttrapport - syntese og analyse av evalueringens delprosjekter. Oslo, Norges forskningsråd [The Norwegian research Council); 2009. 
19. Pedersen PB, Lilleeng SE, Sitter M: Evaluering av Opptrappingsplanen for psykisk helse - supplerende analyser innen spesialisthelsetjenesten [Evaluation of the Plan of Act to Improve Mental Health and Psychiatric Services]. Trondheim, SINTEF Helse; 2009.

20. Tondo L, Albert MJ, Baldessarini RJ: Suicide rates in relation to health care access in the United States: an ecological study. J Clin Psychiatry 2006, 67:517-23.

21. Kapusta ND, Niederkrotenthaler T, Etzersdorfer E, Voracek M, Dervic K, JandlJager E, et al.: Influence of psychotherapist density and antidepressant sales on suicide rates. Acta Psychiatr Scand 2009, 119:236-42.

22. Statistics Norway

[http://statbank.ssb.no/statistikkbanken/Default_FR.asp?PXSid=0\&nvl=true\&P Language $=1 \&$ tilside $=$ selecttable $/$ hovedtabellHjem.asp $\&$ KortnavnWeb $=$ dodsarsa $\mathrm{k}]$

\section{Statistics Norway}

[http://statbank.ssb.no/statistikkbanken/Default_FR.asp?PXSid=0\&nvl=true\&P Language $=1 \&$ tilside $=$ selecttable $/$ hovedtabellHjem. asp \&KortnavnWeb=speshels epsyk]

24. Statistics Norway [http://www.ssb.no/vis/speshelse en/about.html]

25. Denney JT, Rogers RG, Krueger PM, Wadsworth T: Adult Suicide Mortality in the United States: Marital Status, Family Size, Socioeconomic Status, and Differences by Sex. Soc Sci $Q$ 2009, 90:1167.

26. Bramness JG, Walby FA, Tverdal A: The sales of antidepressants and suicide rates in Norway and its counties 1980-2004. $J$ Affect Disord 2007, 102:1-9.

27. Skog OJ, Teixeira Z, Barrias J, Moreira R: Alcohol and suicide--the Portuguese experience. Addiction 1995, 90:1053-61. 
28. Stuckler D, Basu S, Suhrcke M, Coutts A, McKee M: The public health effect of economic crises and alternative policy responses in Europe: an empirical analysis. Lancet 2009, 374:315-23.

29. Sirus RusStat - rusmiddelstatistikk på nett [http://statistikk.sirus.no/sirus/]

30. NorPD: definitions [http://www.norpd.no/Detaljer.aspx]

\section{Statistics Norway}

[http://statbank.ssb.no/statistikkbanken/Default_FR.asp?Productid=04.01\&PXSi $\mathrm{d}=0 \& \mathrm{nvl}=$ true $\&$ PLanguage $=1 \&$ tilside $=$ selecttable $/$ MenuSelP asp \&SubjectCode $=04]$

\section{Statistics Norway}

[http://statbank.ssb.no/statistikkbanken/Default_FR.asp?Productid=06.01\&PXSi $\mathrm{d}=0 \& \mathrm{nvl}=$ true $\&$ PLanguage $=1 \&$ tilside $=$ selecttable $/$ MenuSelP asp \&SubjectCode $=06]$

33. Kuhn L, Davidson LL, Durkin MS: Use of Poisson regression and time series analysis for detecting changes over time in rates of child injury following a prevention program. Am J Epidemiol 1994, 140:943-55.

34. Johannessen HA, Dieserud G, Jakhelln F, Zahl PH, De Leo D: Changes in institutional psychiatric care and suicidal behaviour: a follow-up study of inpatient suicide attempters in Baerum, Norway. Soc Psychiatry Psychiatr Epidemiol 2009, 44:845-51.

35. Shah A, Bhandarkar R, Bhatia G: The relationship between general population suicide rates and mental health funding, service provision and national policy: a cross-national study. Int J Soc Psychiatry 2010, 56:448-53.

36. Lewis G, Appleby L, Jarman B: Suicide and psychiatric services. Lancet 1994, 344:822.

37. Desai RA, Dausey DJ, Rosenheck RA: Mental health service delivery and suicide risk: The role of individual patient and facility factors. $\mathrm{Am} \mathrm{J}$ Psychiatry 2005, 162:311-8. 
38. Prevention of suicide. Part 1: Psychotherapy, drug treatment and electroconvulsive treatment

[http://www.kunnskapssenteret.no/Publikasjoner/534.cms?onepage=1]

39. Linehan MM: Suicide intervention research: a field in desperate need of development. Suicide Life Threat Behav 2008, 38:483-5.

40. Rudd MD: The suicidal mode: a cognitive-behavioral model of suicidality. Suicide Life Threat Behav 2000, 30:18-33.

41. Hawton K, van Heeringen K: Suicide. Lancet 2009, 373:1372-81.

42. Kapusta ND, Etzersdorfer E, Krall C, Sonneck G: Firearm legislation reform in the European Union: impact on firearm availability, firearm suicide and homicide rates in Austria. Br J Psychiatry 2007, 191:253-7.

43. Leenaars AA, Moksony F, Lester D, Wenckstern S: The impact of gun control (Bill C-51) on suicide in Canada. Death Stud 2003, 27:103-24.

44. Etzersdorfer E, Sonneck G: Preventing suicide by influencing mass-media reporting. The Viennese experience 1980-1996. Archives of Suicide Research 1998, 4:67-74.

45. Wasserman D, Varnik A: Suicide-preventive effects of perestroika in the former USSR: the role of alcohol restriction. Acta Psychiatr Scand Suppl 1998, 394:1-4. 


\section{Figures}

Figure 1

Suicide rate per 100000 inhabitants by sex in the period 1990-2006

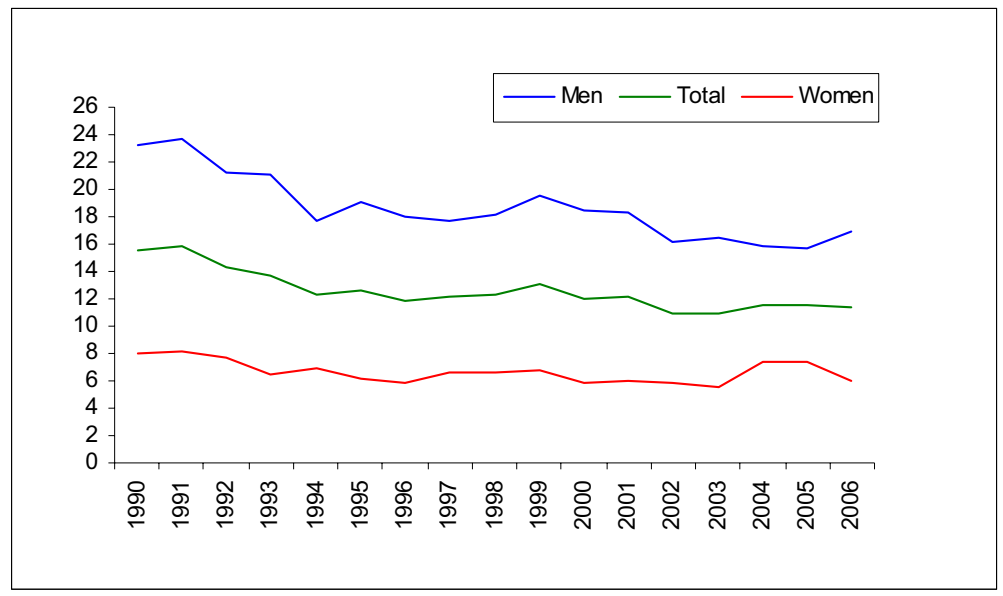




\section{Tables}

Table 1 Changes in national suicide mortality per 100,000 inhabitants and

changes in explanatory variables at the national level by period. Rate ratios are given in parentheses.

\begin{tabular}{lllll}
\hline Variables & $1990-1994(\mathrm{RR})$ & $1995-1999(\mathrm{RR})$ & $2000-2006(\mathrm{RR})$ & $1990-2006(\mathrm{RR})$ \\
\hline Suicide mortality & $15.5-12.2(0.79)$ & $12.6-13.1(1.04)$ & $12.1-11.4(0.94)$ & $15.5-11.4(0.74)$ \\
Discharges $^{1}$ & $6.2-6.9(1.11)$ & $7.5-9.2(1.23)$ & $9.9-13.2(1.33)$ & $6.2-13.2(2.13)$ \\
Outpatient cons. $^{1}$ & $83-122(1.47)$ & $128-148(1.16)$ & $154-267(1.73)$ & $83-267(3.22)$ \\
Beds $^{1}$ & $2.4-2.0(0.83)$ & $1.9-1.7(0.89)$ & $1.7-1.4(0.82)$ & $2.4-1.4(0.58)$ \\
Bed-days $^{1}$ & $774-631(0.82)$ & $617-563(0.91)$ & $545-440(0.81)$ & $774-440(0.57)$ \\
Man-labour years $^{1}$ & $3.98-3.83(0.85)$ & $3.88-4.09(1.05)$ & $4.13-4.61(1.12)$ & $3.98-4.61(1.16)$ \\
Antidepressants $^{2}$ & $11.6-17.8(1.53)$ & $22.5-36.1(1.60)$ & $41-52.5(1.28)$ & $11.6-52.5(4.53)$ \\
Alcohol $^{3}$ & $4.99-4.74(0.95)$ & $4.79-5.45(1.14)$ & $5.66-6.46(1.14)$ & $4.99-6.46(1.29)$ \\
Education $^{4}$ & $12.2-14.2(1.17)$ & $14.8-16.7(1.13)$ & $16.9-19.5(1.15)$ & $12.2-19.5(1.60)$ \\
Unemployment $^{5}$ & $5.2-5.4(1.04)$ & $4.9-3.2(0.65)$ & $3.4-3.5(1.03)$ & $5.2-3.5(0.67)$ \\
\hline
\end{tabular}

${ }^{1}$ Per 1000 inhabitants

${ }^{2}$ Defined daily doses (DDD)/1000 inhabitants/day

${ }^{3}$ Sales of pure alcohol in liters per inhabitant above the age of 15

${ }^{4}$ College and university education per 100 above the age of 16

${ }^{5}$ Unemployed per 100 (age 15-74) 
Table 2 Regional figures of suicide mortality per 100,000 inhabitants in the period 1990-2006; regional figures of five health services variables per 1000 inhabitants in the period 1998-2006; regional figures of the percentage with college and university education and regional figures of the percentage unemployed in the period $1990-2006$. Rate ratios are given in parentheses

\begin{tabular}{|c|c|c|c|c|c|}
\hline Variables & East-region (RR) & South-region (RR) & West region (RR) & Mid-region (RR) & North-region (RR) \\
\hline \multicolumn{6}{|l|}{ Suicide mortality } \\
\hline Men & $26.8-16.8(0.63)$ & $28.7-18.6(0.68)$ & $14.8-16.8(1.14)$ & $30.3-21.5(0.71)$ & $22.8-15.5(0.68)$ \\
\hline Women & $10.7-6.3(0.59)$ & $9.3-8.1(0.87)$ & $4.2-5.2(1.24)$ & $5.2-3.9(0.75)$ & $7.5-5.7(0.76)$ \\
\hline Outpatient consul. & $145-264(1.8)$ & $131-306(2.3)$ & $125-224(1.8)$ & $138-286(2.1)$ & $155-260(1.7)$ \\
\hline Man-labour years & $4.2-5.1(1.21)$ & $3.4-3.8(1.12)$ & $4.1-4.5(1.10)$ & $3.9-4.2(1.07)$ & $4.0-4.7(1.18)$ \\
\hline Discharges & $6.9-12(1.74)$ & $9.3-12.3(1.32)$ & $8.8-13(1.48)$ & $9.5-13.4(1.41)$ & $9-14.8(1.64)$ \\
\hline Beds & $1.8-1.5(0.83)$ & $1.7-1.1(0.65)$ & $1.9-1.5(0.79)$ & $1.7-1.3(0.76)$ & $1.2-1.2(1.0)$ \\
\hline Bed-days & $588-479(0.82)$ & $532-347(0.65)$ & $650-472(0.73)$ & $564-385(0.68)$ & $372-368(0.99)$ \\
\hline \multicolumn{6}{|l|}{ Education } \\
\hline Men & $16.3-21.9(1.35)$ & $11.6-16.3(1.41)$ & $12.4-17.3(1.40)$ & $11.2-16.5(1.47)$ & $9.8-14.4(1.47)$ \\
\hline Women & $13.6-23.2(1.70)$ & $9.6-18.0(1.88)$ & $10.7-20.2(1.89)$ & $9.7-19.4(2.0)$ & $9.1-18.5(2.0)$ \\
\hline \multicolumn{6}{|l|}{ Unemployment } \\
\hline Men & $2.5-2.1(0.84)$ & $2.7-1.4(0.52)$ & $2.9-1.1(0.38)$ & $2.4-1.3(0.54)$ & $3.0-2.0(0.67)$ \\
\hline Women & $1.4-1.3(0.92)$ & $1.5-1.3(0.87)$ & $2.0-1.2(0.60)$ & $1.9-1.3(0.68)$ & $1.8-1.4(0.78)$ \\
\hline
\end{tabular}


Table 3 Poisson regression models of suicide mortality among Norwegian females, with secondary mental health services effect estimates adjusted for annual trends, health regions, sales of antidepressants, sales of alcohol, education and unemployment.

\begin{tabular}{|c|c|c|c|c|c|c|}
\hline \multirow{2}{*}{ Variables } & \multicolumn{2}{|c|}{ Crude analysis } & \multicolumn{2}{|c|}{ Adjusted analysis I $^{I}$} & \multicolumn{2}{|c|}{ Adjusted analysis $\mathrm{II}^{2}$} \\
\hline & IRR & $95 \% \mathrm{CI}$ & IRR & $95 \% \mathrm{CI}$ & IRR & $95 \% \mathrm{CI}$ \\
\hline Year (1990-2006) & $0.99 *$ & $0.981-0.996$ & 1.08 & $0.912-1.289$ & 1.00 & $0.957-1.053$ \\
\hline \multicolumn{7}{|l|}{ Health region } \\
\hline East-region & 1 & & 1 & & 1 & \\
\hline South-region & 0.98 & $0.883-1.084$ & 0.74 & $0.301-1.831$ & 0.98 & $0.883-1.085$ \\
\hline West-region & $0.71 *$ & $0.638-0.800$ & 0.56 & $0.300-1.058$ & $0.71 *$ & $0.638-0.801$ \\
\hline Mid-region & $0.68 *$ & $0.599-0.780$ & 0.52 & $0.236-1.142$ & $0.68^{*}$ & $0.599-0.779$ \\
\hline North-region & $0.79 *$ & $0.682-0.905$ & 0.57 & $0.234-1.400$ & $0.78 *$ & $0.681-0.904$ \\
\hline Outpatient consul. & 1.00 & $0.999-1.000$ & 1.00 & $0.992-1.001$ & & \\
\hline Man-labour years & 1.01 & $0.899-1.132$ & 1.00 & $0.752-1.317$ & & \\
\hline Discharges & $0.97 *$ & $0.952-0.988$ & 1.00 & $0.920-1.076$ & & \\
\hline Beds & $1.19 *$ & $1.057-1.343$ & 0.94 & $0.477-1.870$ & & \\
\hline Bed-days & $1.00 *$ & $1.000-1.001$ & 1.00 & $0.997-1.002$ & & \\
\hline Antidepressants & $1.00 *$ & 0.993-0.999 & $0.97 *$ & 0.944-0.992 & $0.98^{*}$ & $0.967-0.998$ \\
\hline Alcohol & 0.95 & $0.887-1.011$ & $1.76^{*}$ & $1.222-2.543$ & $1.41 *$ & $1.177-1.715$ \\
\hline Education & 0.99 & $0.883-1.113$ & 0.95 & $0.776-1.153$ & & \\
\hline Unemployment & 1.00 & $0.990-1.013$ & 1.11 & $0.914-1.339$ & & \\
\hline$* \mathrm{P}<0.05$ & & & $\begin{array}{l}{ }^{1} \text { Good } \\
\text { chi2 }= \\
\text { Prob }>\end{array}$ & $\begin{array}{l}\text { ess-of-fit } \\
0.4 \\
h i 2(70)=0.19\end{array}$ & $\begin{array}{l}{ }^{2} \text { Good } \\
\text { chi } 2= \\
\text { Prob }>\end{array}$ & $\begin{array}{l}\text { ss-of-fit } \\
4.0 \\
\operatorname{hi} 2(77)=0.27\end{array}$ \\
\hline
\end{tabular}


Table 4 Poisson regression models of suicide mortality among Norwegian males, with secondary mental health services effect estimates adjusted for annual trends, health regions, sales of antidepressants, sales of alcohol, education and unemployment

\begin{tabular}{|c|c|c|c|c|c|c|}
\hline \multirow{2}{*}{ Variables } & \multicolumn{2}{|c|}{ Crude analysis } & \multicolumn{2}{|c|}{ Adjusted analysis I $^{1}$} & \multicolumn{2}{|c|}{ Adjusted analysis $\mathrm{II}^{2}$} \\
\hline & IRR & $95 \% \mathrm{CI}$ & IRR & $95 \% \mathrm{CI}$ & IRR & $95 \% \mathrm{CI}$ \\
\hline Year (1990-2006) & $0.98 *$ & $0.973-0.982$ & 1.07 & $0.988-1.159$ & 1.02 & $0.996-1.045$ \\
\hline \multicolumn{7}{|l|}{ Health region } \\
\hline East-region & 1 & & 1 & & 1 & \\
\hline South-region & $1.09 *$ & $1.025-1.163$ & $0.40 *$ & $0.200-0.799$ & $0.46^{*}$ & $0.299-0.717$ \\
\hline West-region & $0.79 *$ & $0.741-0.851$ & $0.32 *$ & $0.176-0.580$ & $0.38^{*}$ & $0.260-0.553$ \\
\hline Mid-region & $1.25^{*}$ & $1.168-1.335$ & $0.44^{*}$ & $0.212-0.907$ & $0.51 *$ & $0.321-0.802$ \\
\hline North-region & 1.00 & $0.922-1.083$ & $0.28 *$ & $0.114-0.690$ & $0.33^{*}$ & $0.184-0.581$ \\
\hline Outpatient consul. & $1.00 *$ & $0.998-1.000$ & 1.01 & $0.998-1.003$ & & \\
\hline Man-labour years & $0.76^{*}$ & $0.709-0.818$ & 0.89 & $0.750-1.048$ & & \\
\hline Discharges & $0.96^{*}$ & $0.946-0.967$ & 1.00 & $0.950-1.056$ & & \\
\hline Beds & $1.30^{*}$ & $1.215-1.399$ & 1.15 & $0.785-1.700$ & & \\
\hline Bed-days & $1.00 *$ & $1.000-1.001$ & 1.00 & $0.999-1.003$ & & \\
\hline Antidepressants & $0.99 *$ & $0.991-0.994$ & 1.00 & $0.985-1.012$ & & \\
\hline Alcohol & $0.85^{*}$ & $0.818-0.884$ & 0.91 & $0.738-1.131$ & & \\
\hline Education & $0.98 *$ & $0.968-0.982$ & $0.83 *$ & $0.722-0.942$ & $0.86^{*}$ & $0.785-0.940$ \\
\hline Unemployment & $1.11 *$ & $1.075-1.147$ & $0.92 *$ & $0.859-0.985$ & $0.91^{*}$ & $0.849-0.966$ \\
\hline \multirow[t]{2}{*}{$* \mathrm{P}<0.05$} & & & \multicolumn{2}{|c|}{$\begin{array}{l}{ }^{1} \text { Goodness-of-fit } \\
\text { chi } 2=73.2\end{array}$} & \multicolumn{2}{|c|}{$\begin{array}{l}{ }^{2} \text { Goodness-of-fit } \\
\text { chi } 2=79.5\end{array}$} \\
\hline & & & \multicolumn{2}{|c|}{ Prob $>\operatorname{chi} 2(70)=0.37$} & \multicolumn{2}{|c|}{ Prob $>\operatorname{chi} 2(77)=0.40$} \\
\hline
\end{tabular}





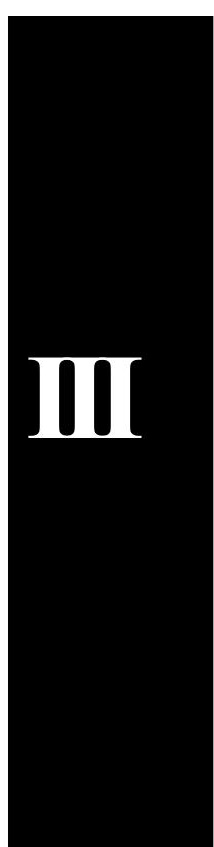





\section{Chain of care for patients who have attempted suicide: a follow-up study from Bærum, Norway.}

Håkon A. Johannessen ${ }^{1 \S}$, Gudrun Dieserud ${ }^{1}$, Diego De Leo ${ }^{2}$, Bjørgulf Claussen ${ }^{3}$, PerHenrik Zahl ${ }^{1}$

Address: ${ }^{1}$ Department of Suicide Research and Prevention, Division of Mental Health, Norwegian Institute of Public Health, Oslo, Norway

${ }^{2}$ Australian Institute for Suicide Research and Prevention, Mt Gravatt Campus, GriffithUniversity, Brisbane, Australia

${ }^{3}$ Institute of General Practice and Community Health, Section for Social Medicine, University of Oslo, Oslo, Norway

${ }^{\S}$ Corresponding author

Email:

HAJ: hajn@,fhi.no

GD: gudrun.dieserud@fhi.no

DDL: d.deleo@griffith.edu.au

BC: bjorgulf.claussen@medisin.uio.no

PHZ: per-henrik.zahl@,fhi.no 


\section{Abstract}

\section{Background}

Individuals who have previously attempted suicide are at greater risk of subsequent suicidal behaviour. Since 1983, a community-based suicide prevention team has been operating in the municipality of Bærum, Norway. This study aimed to test the effectiveness of the team's interventions in preventing repeated suicide attempts and suicide deaths, as part of a chain of care model for all general hospital treated suicide attempters.

\section{Methods}

Data has been collected consecutively since 1984 and a follow-up was conducted on all individuals who were admitted to the general hospital after a suicide attempt. The risk of a repeated suicide attempt and suicide were comparatively examined in those subjects who received assistance from the suicide prevention team in addition to 'treatment as usual', and in those who only received 'treatment as usual'. Logistic regression and Cox regression were used to analyse the data.

\section{Results}

Between January 1984 and December 2007, 1,616 subjects were registered as having attempted suicide; 197 of them (12\%) made another attempt within 12 months. Compared to subjects who did not receive assistance from the suicide prevention team, individuals involved in the prevention program did not have a significantly different risk of a repeated attempt within six months (adjusted $O R=1.08 ; 95 \% \mathrm{CI}=0.66$ - 
1.74), twelve months (adjusted $O R=0.86 ; 95 \% \mathrm{CI}=0.57-1.30$ ), or five years (adjusted $R R=0.90 ; 95 \% \mathrm{CI}=0.67-1.22$ ) after their first recorded attempt. Nor did we find any differences in the risk of committing suicide (adjusted $R R=0.85 ; 95 \% \mathrm{CI}$ $=0.46-1.57)$. Previous suicide attempts, marital status and employment status were significantly associated with a repeated suicide attempt within six and twelve months $(\mathrm{p}<0.05)$. Within five years, alcohol misuse, employment status, and previous suicide attempts were significantly associated with a repeated attempt $(\mathrm{p}<0.05)$; in contrast, marital status became non-significant $(\mathrm{p}>0.05)$. With each year of age, the risk of suicide increased by $3 \%(\mathrm{p}<0.05)$.

\section{Conclusions}

The present study did not find any differences in the risk of fatal and non-fatal suicidal behaviours between subjects who received assistance from the community suicide prevention team in addition to 'treatment as usual' and subjects who received only 'treatment as usual'. However, assistance from the community team was mainly offered to attempters who were not receiving sufficient support from 'treatment as usual', and was accepted by $50-60 \%$ of those deemed eligible. Thus, obtaining similar outcomes for individuals, all of whom were clinically judged to have different needs, could in itself be considered a desirable result.

\section{Key words}

Suicide attempt, repetition, community-based programs, suicide prevention team. 


\section{Background}

Attempted suicide is a serious public health problem. The National Co-morbidity Study reported a life-time prevalence of $4.6 \%$ for this phenomenon [1], a figure substantially similar to the one derived from a large Australian community survey (4.2\%) [2]. Furthermore, the risk of subsequent suicidal behaviour is substantial: about $15 \%$ of those who attempt suicide repeat the act within one year [3]. Further, the suicide risk for males and females who have previously attempted suicide has been reported to be 55 and 77 times that of the general male and female population, respectively [4]. Consequently, effective after-care strategies aimed at individuals who have attempted suicide are important [5].

Although various psychosocial and pharmacological treatments in preventing subsequent suicidal behaviour have been developed, the evidence-based knowledge of which treatments or strategies are most effective is limited [6-9]. Due to the low rate of suicide, it is difficult to test the effectiveness of intervention strategies that aim to prevent suicide among suicide attempters [9-11]. For example, given that the risk of committing suicide in this group is $2.8 \%$, Gunnell and Frankel [6] estimated that a total sample size of almost 45,000 subjects would be needed to demonstrate a $15 \%$ reduction of suicide risk. Therefore, a repeated suicide attempt has been used as a reasonable proxy because it occurs more frequently and it is strongly related to suicide [9-12]. Further, a repeated suicide attempt is obviously an outcome that should be prevented. It indicates consistent distress for the individual and results in considerable health care costs [9]. However, limited sample size has been a frequent issue in studies that have considered repeated suicide attempts as outcome measure. Consequently, a 
very limited number of investigations have managed to detect clinically meaningful and statistically significant intervention's effects [9].

Recently, Hvid and Wang [13] published a study on the effectiveness of an outreach intervention aimed at individuals who had attempted suicide. They found that individuals in the intervention group, who were offered follow-up care by a rapid response outreach program, had a lower rate of repeated suicide attempts than the control group $(R R=0.43 ; 95 \% \mathrm{CI}=0.23-0.80)$. Some other studies have also indicated the effects of interventions that practice active outreach and contact maintenance on a regular basis after a person attempts suicide [14-17]. In Norway, a suicide intervention model, similar to the one studied by Hvid and Wang, has been in effect since 1983 in a municipality outside the capital. This intervention is communitybased and flexibly serves the individual by creating a multi-targeted, coordinated and long lasting chain of care. The objective of the present study was to investigate if individuals assisted by a suicide prevention team organised by the community health services had a similar risk of repeated suicide attempts and/or suicide than individuals who were not assisted by this team, but referred for "treatment as usual."

\section{METHODS}

\section{The Bærum Model}

A rapid-response intervention is created through collaboration between the general hospital of Asker and Bærum, the municipal suicide prevention team and community health and social services located in the municipality of Bærum. On presentation at the 
hospital or emergency unit, patients receive acute life-saving treatment and medical monitoring. Consequently, a hospital-based suicide prevention team, including social workers and a liaison psychiatrist, is notified. This team helps the patients through crisis intervention and evaluates the patients' psychosocial functioning and risk for suicide. Appropriate measures are then taken with the patients' cooperation. These measures can include referrals to psychiatric inpatient and various outpatient services, including mental health treatment, substance abuse treatment, family counselling and various social services.

All patients that are not immediately admitted to psychiatric inpatient treatment are evaluated for referrals to the community suicide prevention team. Only a few of those patients admitted to inpatient mental health treatment receive community suicide prevention team services ( 28 in the present study). The community team and the hospital team collaborate to ensure a joint evaluation of the situation, to make appropriate referrals, and to make all parts of the follow-up effective as soon as possible. Main patient groups eligible for referrals to the suicide prevention team are as follows:

- Patients in need of outpatient health and social services that are not established by the hospital team

- Patients in ongoing outpatient treatment who are in need of extra support

- Patients and family or other who are in relational conflicts and in need of extra support

- Patients who have previously dropped out of mental health treatment and need to be motivated to reappoint. 
The community suicide prevention team includes public health nurses and a psychologist. The nurses organise the work in relation to patients, in consultation with the psychologist. A particular emphasis is placed on the suicidal person's need for a supportive helper. On average, $50-60 \%$ of the attempters deemed eligible for the community team is referred to this follow-up yearly.

If patients agree to be assisted by this team, a public health nurse contacts them shortly after discharge. A telephone call is made, preferably the day of discharge or the day after. An agreement is made on when and where to meet, and in most cases the agreement is that the nurse is making a home visit within a few days. These nurses act as "ombudsmen" [18]: the main aim is to ensure that the patients are given sufficient follow-up care by specialist mental health services or community health/social services within an acceptable period of time following hospital discharge. Further, the nurse motivates the patient to accept treatment and better adhere to treatment appointments. If patients drop out of treatment, the nurse tries to recuperate them back into treatment or establishes a more suitable therapeutic plan in collaboration with the patient and the health services.

In addition, the nurse fulfils the role of looking after the patient in between hospital discharge and established aftercare. The nurse gives the patient "psychological first aid", problem-solving counselling, and activates the patient's social network. Although the main aim is reached when a treatment program is established, the patient is followed-up by the nurse for approximately one year to secure continuity, treatment compliance and social support. Most of the contact will be phone calls, ranging from 
several times a week in the beginning, to a monthly call at the end of the follow-up period.

The intervention offered by this team is not regarded as stand-alone treatment, but rather as a service offered in addition to established health and social services; it is not a substitute of any other health services. If the standard follow-up treatment is deemed to be sufficient, the community team is not activated. Patients are in any case free to reject assistance from the community team.

\section{Data}

The data set comprised of unselected individuals, who were residents of the municipality of Bærum and admitted to the general hospital after a suicide attempt between $1^{\text {st }}$ January 1984 and $31^{\text {st }}$ December 2008 . The municipality of Bærum is a suburb located on the outskirts of Oslo, the capital of Norway [19]. Compared to the national average, Bærum is characterised by a higher population density, a higher income and education level for both men and women, and a lower unemployment rate. In 1984, the population of Bærum, aged above 15 years, was 71,237 (34,306 males and 36,931 females); in 2008, it was 80,368 (38,463 males and 41,905 females).

Data were collected in two stages. Firstly, data on individuals who had made a suicide attempt were consecutively collected from 1984 [20] using records from the local hospital in Bærum and the Municipal Health Services office. A quality control auditing was performed by rechecking all entered data. The definitional criteria for 'attempted suicide' were similar to those of 'parasuicide' used in the WHO/EURO Multicentre Study on Suicidal Behaviour: "An act with nonfatal outcome, in which an individual 
deliberately initiates a non-habitual behaviour that, without intervention from others, will cause self-harm, or deliberately ingests a substance in excess of the prescribed or generally recognised therapeutic dosage, and which is aimed at realising changes which the subject desired via the actual or expected physical consequences"[21]. Secondly, data on mortality of all causes were collected by linking the personal identifier of individuals who had made a suicide attempt to the computerised Causesof-Death Registry at Statistics Norway. This registry has an almost complete registration of causes of death. Prior to 1986 , causes of deaths were classified according to the International Classification of Diseases Eight Revision (ICD-8), from1986-1995 according to the ICD-10 and from 1996 onwards according to the ICD-10.The last date of mortality information in the present data set was 31 December 2003.

The outcome variable 'repeated suicide attempt' was defined as a new record of suicide attempt within six months, twelve months and five years after the index attempt. The index attempt refers to the first recorded suicide attempt. In order to be recorded, the reattempt had to lead to emergency unit or hospital admittance in Asker $\&$ Bærum. Variables entered into the analyses at the time of the index attempt were: suicide prevention team assistance, age, sex, aftercare referrals, alcohol misuse, marital status, employment status, and previous suicide attempts. The classification of these variables was based on information from medical records and information given by patients when interviewed at the hospital or by personnel in the community health services. 
The variable 'aftercare referrals' provides information on the type of standard followup treatment given to the individual; it also functions as a proxy measure of the kind of problems the attempter is presenting. In the regression analysis, psychiatric outpatient services, addiction services and family services were grouped together and labelled as 'Psychiatric outpatient services'; psychiatric hospital care was labelled as 'Psychiatric hospital care'; and social services, child care, home care, private practice psychotherapists, and other forms of care (or any) were grouped together and labelled as 'Other'.

All Norwegian citizens that are identified as ill have the right to adequate health care treatment, as stated by Norwegian health authorities. As a basic principle, health care treatment is voluntary. The patient group that did not receive any standard aftercare may have been evaluated as not in need of specific aftercare or may have refused the recommended treatment. The main motive for referrals to the suicide prevention team, which is not defined as health care treatment in terms of Norwegian law, is as follows: all patients who are admitted to the general hospital or emergency unit due to an attempted suicide are eligible to be offered assistance by a rapid outreach suicide prevention team, organised by the community health services, except patients that immediately after discharge are admitted to inpatient psychiatric care. Assistance from the suicide prevention team is voluntary; hence, patients are free to refuse it.

\section{Statistics}

Logistic regression analyses were computed to estimate the risk for a repeated suicide attempt within 6 and 12 months following the first recorded suicide attempt. Cox regression analyses were computed to estimate the risk for a repeated suicide attempt 
within 5 years of follow-up and to estimate the risk for suicide. In the Cox regression analyses, the individuals were followed for different lengths of time. When the outcome was a repeated suicide attempt, the period of risk was estimated in months from the date of the first recorded suicide attempt to the occurrence of a new attempt, or to the end of the five year follow-up period or to the end of the study (December 2008), whichever happened first. When the outcome was suicide, the period of risk was estimated in months from the date of the first recorded suicide attempt to death by all causes or to the end of study (December 2003), whichever happened first.

In order to perform this investigation, permission was obtained from the Norwegian Data Inspectorate, The Regional Committee for Medical Research Ethics and the Norwegian Directorate of Health. Further, a Data Handling Treaty between the Hospital of Asker \& Bærum and the Norwegian Institute of Public Health was obtained.

\section{Results}

Between January 1984 and December 2007, 1,616 individuals were registered for a suicide attempt. Of these, $197(12.2 \% ; 95 \% \mathrm{CI}=10.6-14.0)$ repeated the attempt within 12 months of follow-up. Among the 1,616 individuals, 1,311 were eligible for an evaluation to be referred to the suicide prevention team. Information on whether these received assistance from the suicide prevention team was recorded for 1,304 individuals (missing $=7) ; 675(52 \%)$ of them did actually receive the assistance (Table 1 and 2). Of these, 531 (79\%) were also referred to other types of health or social services, while $140(21 \%)$ were not referred to such services (missing = 4). Among the $629(48 \%)$ individuals who did not receive assistance from the team, $435(69 \%)$ were 
referred to other types of health or social services, while $172(27 \%)$ were not referred to such services $($ missing $=22)($ Table 2$)$.

Among the 675 individuals who received assistance from the suicide prevention team, $60(9 \%)$ repeated an attempt within six months of their index episode, and $80(12 \%)$ repeated within twelve months; 47 (7\%) of those who did not receive assistance from the team repeated within six months and $70(11 \%)$ repeated within twelve months (Table 2). As seen in Table 3, the odds ratio (OR) of a repeated suicide attempt within six months (adjusted $O R=1.14)$ and twelve months (adjusted $O R=0.93$ ) were not significantly associated with the suicide prevention team variable, or the other aftercare options.

Previous suicide attempts, marital status and employment status were significantly associated with a repeated suicide attempt within both six and twelve months $(P<$ 0.05) (Table 3). Individuals who made several suicide attempts prior to their index attempt had more than two-times the increased odds ratio of a consequent suicide attempt within both six months and twelve months. Being married/cohabitant and being a student/pupil were associated with a significantly reduced odds ratio of a consequent suicide attempt within both six and twelve months.

Data were also analysed separately for men and women. Neither men nor women who received assistance from the suicide prevention team had a reduced adjusted odds ratio of a repeated suicide attempt (suicide attempt repeat within twelve months for women: adjusted $O R=0.69 ; P<0.14)$. 
The suicide prevention team's working routines were reshaped and improved in 1998. Therefore we studied if there were any differences between the periods by analysing the periods 1984-1997 and 1998-2007 separately. No significant differences emerged. Finally, we analysed the odds of a third suicide attempt being made within twelve months from the second attempt. Again, no differences were detectable in relation to the suicide prevention team variable (adjusted $O R=1.37 ; P>0.05$ ).

In Table 4, Cox regression analyses were computed in order to study if the suicide prevention team influenced suicide attempt repetition within a five-year follow-up period. It was found that receiving assistance from the suicide prevention team was not significantly associated with a repeated suicide attempt (adjusted $R R=0.90 ; P>$ 0.05 ). In general, being a student/pupil (adjusted $R R=0.47 ; P<0.05$ ) significantly reduced the risk; several previous suicide attempts (adjusted $R R=2.20 ; P<0.05$ ) and alcohol misuse (adjusted $R R=1.59 ; P<0.05$ ) increased the risk.

We also computed analyses in which patients admitted to inpatient psychiatric care were included, in total 1616 subjects. Assistance from the community team was given to very few in the inpatient group. The results showed that receiving assistance from the suicide prevention team was not significantly associated with a repeated suicide attempt within 6 months (adjusted $O R=1.14 ; P>0.05), 12$ months (adjusted $O R=$ $0.93 ; \mathrm{P}>0.05$ ) or 5 years (adjusted $R R=0.94 ; P>0.05$ ) of follow-up.

Between 1984 and 2003, a total of 247 deaths among 1,422 individuals were recorded. Of these, 55 (22\%) were caused by suicide. Among the 1,422 individuals, it was possible to follow the risk of committing suicide within 1 year for 1,357 subjects, and 
within 9 years for 895 subjects. No significant differences in suicide risk were observed between the two groups within 1 year - the rate ratio (RR) was 0.33 (95\% CI $=0.09-1.25)$ and 9 years of follow-up $(R R=0.73 ; 0.36-1.48)$, respectively. After adjustments for concurrent variables (Table 5), there was no significant difference in suicide risk between patients who were assisted by the suicide prevention team and patients who were not (adjusted $R R=0.85 ; 95 \% \mathrm{CI}=0.46-1.57$ ). Age was significantly associated with suicide mortality: each year increased the risk for suicide by 1.03 times $(95 \% \mathrm{CI}=1.01-1.04)$.

\section{Discussion}

The objective of the present study was to investigate if there was any difference in the risk of repeated suicide attempt and/or suicide, depending on whether suicide attempters received assistance from a suicide prevention team in addition to treatment as usual or not. When compared to individuals who were not assisted in the same way, a significantly reduced risk of a repeated suicide attempt was not observed at six or twelve months or at five years. The results were similar in the crude and the adjusted analyses. Neither did we observe a significantly reduced suicide risk among individuals who were assisted by the suicide prevention team.

Previous suicide attempts, marital status and employment status were significantly associated with a repeated suicide attempt within both six and twelve months $(P<$ 0.05). Individuals who had made several suicide attempts prior to their index attempt had more than two-times the increased (adjusted) odds ratio of a repeated suicide attempt, at both six months and twelve months. Being married/cohabitant and being a student/pupil were associated with reduced adjusted odds ratio of a repeated suicide 
attempt for the same time intervals. At five-year follow-up, alcohol misuse and gender were significantly associated with repeated attempt, whereas marital status became non-significant. Male gender and being a student/pupil reduced the risk by $19 \%$ and $53 \%$ respectively; several previous suicide attempts and alcohol misuse increased the risk by 2.20 and 1.59 times, respectively. Thus, in the present study, a history of previous suicide attempts was the strongest predictor for both short- and long-term repeated suicide attempts. A similar finding was also documented by other researchers $[3,13,22]$. Regarding suicide, only age was significantly associated with suicide mortality: the risk was increasing by 3 percent for each year. Older age is a well known risk factor reported in the literature for subsequent suicide in individuals who have previously attempted $[23,24]$.

To determine with the highest level of scientific certainty the effectiveness of interventions, studies need to be designed as randomised-controlled trials. Due to ethical and practical reasons, the present study had a naturalistic design. The Bærum Model implies an individual evaluation of needs, and assistance by the community suicide prevention team may not be relevant for all eligible patients. Thus, randomization to community team or not would break with the clinical guidelines for the model and the health care personnel. Consequently, patients were not randomised to either intervention or control in our study, nor did we have data on a comparable control group prior to the start of the intervention in 1983. Thus, the lack of control group in our study makes us unable to firmly conclude in one direction or the other, but we simply state that there were no detectable differences in risk for repeated attempts and suicide between individuals who did or did not receive assistance from the suicide prevention team. Regression analyses can only adjust for confounders, 
while selection bias can only be handled by randomisation. Both self-selection by patients and selection by health care personnel may have biased our study. Patients were free to choose whether to accept or not the assistance offered by the suicide prevention team. On the other hand, health care personnel could choose not to offer team assistance when circumstances were considered as inappropriate or of no particular concern. Consequently, these types of selection may have influenced obtained results. On the other hand, in line with the philosophy of the Bærum model, one would expect that an efficient model of referral and care eventually permit suicide attempters - with or without the assistance of the community team - to obtain the same prognosis in terms of suicidal behaviour repetition, either fatal or non-fatal.

Further, it was assumed that all interventions carried out at the hospital level were similar. As described above, a suicide prevention team including social workers and a psychiatrist is activated at the hospital immediately after emergency treatment is provided. All individuals who have attempted suicide, and are admitted to a medical ward, receive crisis intervention at the hospital. Appropriate measures are evaluated with the patient's cooperation before further referrals are made. This sequence of interventions may have per se a protective effect on future suicidal behaviour; as a matter of fact, in Bærum the total incidence of repeated suicide attempts was $12 \%$ (95\% CI $=10.7$ to 14.1$)$. This is significantly below the average repeated suicide attempt rate of about $15 \%$ reported in a systematic review by Owens et al [3]. In the same study, Owens et al reported a suicide mortality rate between $0.5 \%$ and $2 \%$ one year after the suicide attempt and above 5\% after nine years. The figures for Bærum were fairly similar: $1.1 \%(95 \% \mathrm{CI}=0.67-1.83)$ after one year, but $4.6 \%(95 \% \mathrm{CI}=$ 3.37-6.22) after nine years. 
The positive outcomes described by Hvid and Wang [13] happened in a context that might be comparable to the Norwegian Bærum model. However, their study involved a quasi-experimental design, which was not possible to endorse in the present investigation. Perhaps in the future, in Norway, it will be feasible comparing the incidence of repeated suicide attempts in hospitals with and without a chain of care structure [25]. Variables such as compliance to treatment [26] and quality of life should be controlled in order to verify their possible impact of chain of care interventions [25].

\section{Conclusions}

This study did not detect significant differences in the risk of subsequent suicidal behaviour between subjects whose aftercare involved a suicide prevention communitybased service in addition to treatment as usual and those who were only followed by treatment as usual. Apparently disappointing, this result might actually indicate that the chain of care model is at least able to render indistinguishable - in terms of outcomes - subjects who are judged as more needy from those who are less needy. Of course, only a randomized-control trial could provide evidence of the effectiveness of the Bærum model. Within twelve months, an incidence of $12 \%$ for repeated suicide attempts was observed in the municipality of Bærum (psychiatric inpatients included), a figure slightly lower than the $15 \%$ reported in the literature. Whether this relatively lower incidence is related or not to the suicide prevention system in operation at hospital and community level remains unclear. 


\section{Competing interests}

None

\section{Authors' contributions}

HAJ made substantial contributions to conception and design of the manuscript, drafted the manuscript, analyzed and interpreted the data, and critically revised the manuscript for important intellectual content. GD has been a central figure in organising the Bærum Model. She has been in charge of data collection since 1984, and has substantially contributed to the draft of this paper. DDL made substantial contributions to conception and design of the manuscript, interpreted the data, and critically revised the manuscript for important intellectual content. BC critically revised the manuscript for important intellectual content. PHZ has helped with data analysis and interpretation, and critically revised the manuscript for important intellectual content. All of the authors have read and approved this final manuscript.

\section{Acknowledgements}

This study was funded by the Research Council of Norway. We are grateful to Fredrik Jakhelln and Aslaug Fagernes at Bærum general hospital for participating in the data collection procedures. We thank Melanie Straiton at the Norwegian Institute of Public Health and Kathy McKay at Griffith University for language editing. 


\section{References}

1. Kessler RC, McGonagle KA, Zhao S, Nelson CB, Hughes M, Eshleman S, et al.:

Lifetime and 12-month prevalence of DSM-III-R psychiatric disorders in the United States. Results from the National Comorbidity Survey. Arch Gen Psychiatry 1994, 51:8-19.

2. De Leo D, Cerin E, Spathonis K, Burgis S: Lifetime risk of suicide ideation and attempts in an Australian community: prevalence, suicidal process, and helpseeking behaviour. $J$ Affect Disord 2005, 86:215-24.

3. Owens D, Horrocks J, House A: Fatal and non-fatal repetition of self-harm Systematic review. Br J Psychiatry 2002, 181:193-9.

4. Ostamo A, Lonnqvist J: Excess mortality of suicide attempters. Soc Psychiatry Psychiatr Epidemiol 2001, 36:29-35.

5. Hawton K, Van Heeringen K: Suicide. Lancet 2009, 373:1372-81.

6. Gunnell D, Frankel S: Prevention of suicide: aspirations and evidence. BMJ 1994, 308:1227-33.

7. Mann JJ, Apter A, Bertolote J, Beautrais A, Currier D, Haas A, et al.: Suicide prevention strategies: a systematic review. JAMA 2005, 294:2064-74.

8. Rodgers PL, Sudak HS, Silverman MM, Litts DA: Evidence-based practices project for suicide prevention. Suicide Life Threat Behav 2007, 37:154-64. 
9. Hawton K, Arensman E, Townsend E, Bremner S, Feldman E, Goldney R, et al.: Deliberate self harm: systematic review of efficacy of psychosocial and pharmacological treatments in preventing repetition. $\mathrm{Br}$ Med $J$ 1998, 317:441-7.

10. Goldney RD: Suicide prevention: a pragmatic review of recent studies. Crisis 2005, 26:128-40.

11. Goldney RD: Suicide prevention is possible: A review of recent studies. Archives of Suicide Research 1998, 4:329-39.

12. Beautrais AL: Suicides and serious suicide attempts: two populations or one? Psychol Med 2001, 31:837-45.

13. Hvid M, Wang AG: Preventing repetition of attempted suicide--I. Feasibility (acceptability, adherence, and effectiveness) of a Baerum-model like aftercare. Nord J Psychiatry 2009, 63:148-53.

14. Hepp U, Wittmann L, Schnyder U, Michel K: Psychological and psychosocial interventions after attempted suicide: an overview of treatment studies. Crisis 2004, 25:108-17.

15. Guthrie E, Kapur N, Mackway-Jones K, Chew-Graham C, Moorey J, Mendel E, et al.: Randomised controlled trial of brief psychological intervention after deliberate self poisoning. $B M J 2001,323: 135-8$.

16. Welu TC: A follow-up program for suicide attempters: evaluation of effectiveness. Suicide Life Threat Behav 1977, 7:17-20. 
17. Nordentoft M, Branner J, Drejer K, Mejsholm B, Hansen H, Petersson B: Effect of a Suicide Prevention Centre for young people with suicidal behaviour in Copenhagen. Eur Psychiatry 2005, 20:121-8.

18. Shneidman ES: Definition of suicide: John Wiley \& Sons. Toronto: 1985.

19. Statistics Norway: [http://www.ssb.no/english/municipalities/0219]

20. Dieserud G, Loeb M, Ekeberg O: Suicidal behavior in the municipality of Baerum, Norway: A 12-year prospective study of parasuicide and suicide. Suicide Life Threat Behav 2000, 30:61-73.

21. Platt S, BilleBrahe U, Kerkhof A, Schmidtke A, Bjerke T, Crepet P, et al.: Parasuicide in Europe - the Who Euro Multicenter Study on Parasuicide .1. Introduction and Preliminary-Analysis for 1989. Acta Psychiatr Scand 1992, 85:97-104.

22. Tejedor MC, Diaz A, Castillon JJ, Pericay JM: Attempted suicide: repetition and survival--findings of a follow-up study. Acta Psychiatr Scand 1999, 100:205-11.

23. Skegg K: Self-harm. Lancet 2005, 366:1471-83.

24. Zahl DL, Hawton K: Repetition of deliberate self-harm and subsequent suicide risk: long-term follow-up study of 11583 patients. Br J Psychiatry 2004, 185:70-5.

25. Rossow I, Mehlum L, Gjertsen F, Moller B: Chain of care for patients with intentional self-harm: an effective strategy to reduce suicide rates? Suicide Life Threat Behav 2009, 39:614-22. 
26. Van Heeringen C, Jannes S, Buylaert W, Henderick H, De Bacquer D, Van Remoortel J: The management of non-compliance with referral to out-patient after-care among attempted suicide patients: a controlled intervention study. Psychol Med 1995, 25:963-70. 


\section{Tables}

Table 1 - Repeated suicide attempts within 12 months by sex and suicide prevention team

\begin{tabular}{lllllll}
\hline & Men & \multicolumn{3}{c}{ Woman } & \multicolumn{3}{c}{ Total } \\
$\begin{array}{l}\text { Suicide } \\
\text { prevention } \\
\text { team }\end{array}$ & $N$ & Cases (\%) & $N$ & Cases (\%) & $N$ & Cases (\%) \\
\hline Yes & 182 & $26(14)$ & 493 & $54(11)$ & 675 & $80(12)$ \\
No & 231 & $20(9)$ & 398 & $50(13)$ & 629 & $70(11)$ \\
Total & 413 & $46(11)$ & 891 & $104(12)$ & 1304 & $150(12)$ \\
\hline
\end{tabular}


Table 2 - Characteristics of the index attempt by suicide prevention team.

\begin{tabular}{|c|c|c|c|c|c|}
\hline \multirow[b]{2}{*}{ Variables } & \multirow{2}{*}{\multicolumn{2}{|c|}{$\begin{array}{l}\text { No suicide } \\
\text { prevention team } \\
\text { assistance } \\
N=629 ; 48 \%\end{array}$}} & \multirow{2}{*}{\multicolumn{2}{|c|}{$\begin{array}{l}\text { Suicide prevention } \\
\text { team assistance } \\
N=675 ; 52 \%\end{array}$}} & \multirow{2}{*}{$\begin{array}{l}\text { Total } \\
N=1304\end{array}$} \\
\hline & & & & & \\
\hline \multicolumn{6}{|l|}{ Aftercare referrals } \\
\hline None & 172 & $55 \%$ & 140 & $45 \%$ & 312 \\
\hline Psychiatric out-patient & 111 & $44 \%$ & 143 & $56 \%$ & 254 \\
\hline Addiction services & 63 & $39 \%$ & 100 & $61 \%$ & 163 \\
\hline Family services & 35 & $24 \%$ & 109 & $76 \%$ & 144 \\
\hline Social services & 6 & $18 \%$ & 27 & $82 \%$ & 33 \\
\hline Home care & 61 & $78 \%$ & 17 & $22 \%$ & 78 \\
\hline Private Psychotherapist & 47 & $42 \%$ & 66 & $58 \%$ & 113 \\
\hline Child care & 34 & $64 \%$ & 19 & $36 \%$ & 53 \\
\hline Other & 78 & $61 \%$ & 50 & $39 \%$ & 128 \\
\hline Missing & 22 & $85 \%$ & 4 & $15 \%$ & 26 \\
\hline \multicolumn{6}{|l|}{ Sex } \\
\hline Male & 231 & $56 \%$ & 182 & $44 \%$ & 413 \\
\hline Female & 398 & $45 \%$ & 493 & $55 \%$ & 891 \\
\hline Missing & 0 & $0 \%$ & 0 & $0 \%$ & 0 \\
\hline \multicolumn{6}{|l|}{ Age } \\
\hline 15-19 & 99 & $44 \%$ & 124 & $56 \%$ & 223 \\
\hline $20-29$ & 150 & $46 \%$ & 177 & $54 \%$ & 327 \\
\hline $30-39$ & 120 & $51 \%$ & 117 & $49 \%$ & 237 \\
\hline $40-49$ & 103 & $45 \%$ & 129 & $55 \%$ & 231 \\
\hline $50-59$ & 61 & $48 \%$ & 67 & $52 \%$ & 128 \\
\hline $60+$ & 95 & $60.5 \%$ & 62 & $39.5 \%$ & 157 \\
\hline Missing & 1 & $100 \%$ & 0 & $0 \%$ & 1 \\
\hline \multicolumn{6}{|l|}{ Previous attempts } \\
\hline None & 339 & $42 \%$ & 462 & $58 \%$ & 801 \\
\hline One & 93 & $42 \%$ & 128 & $58 \%$ & 221 \\
\hline Several & 40 & $38 \%$ & 65 & $62 \%$ & 105 \\
\hline Missing & 157 & $89 \%$ & 20 & $11 \%$ & 177 \\
\hline \multicolumn{6}{|l|}{ Alcohol misuse } \\
\hline No & 513 & $49.5 \%$ & 524 & $50.5 \%$ & 1037 \\
\hline Yes & 116 & $43 \%$ & 151 & $57 \%$ & 267 \\
\hline Missing & 0 & $0 \%$ & 0 & $0 \%$ & 0 \\
\hline \multicolumn{6}{|l|}{ Marital status } \\
\hline Married/cohabiting & 195 & $42 \%$ & 273 & $58 \%$ & 468 \\
\hline Single & 243 & $49 \%$ & 250 & $51 \%$ & 493 \\
\hline Widow(er) & 34 & $65 \%$ & 18 & $35 \%$ & 52 \\
\hline Divorced/separated & 84 & $39 \%$ & 131 & $61 \%$ & 215 \\
\hline Missing & 73 & $96 \%$ & 3 & $4 \%$ & 76 \\
\hline \multicolumn{6}{|l|}{ Employment status } \\
\hline Employed & 145 & $32 \%$ & 307 & $68 \%$ & 452 \\
\hline Unemployed/disabled & 91 & $42 \%$ & 128 & $58 \%$ & 219 \\
\hline Student/pupil & 88 & $43 \%$ & 117 & $57 \%$ & 205 \\
\hline Others & 112 & $55 \%$ & 92 & $45 \%$ & 204 \\
\hline Missing & 193 & $86 \%$ & 31 & $14 \%$ & 224 \\
\hline
\end{tabular}


Table 3 - Logistic regression analysis predicting repeated suicide attempt within 6 and 12 months after the index attempt, respectively.

\begin{tabular}{|c|c|c|c|c|c|c|c|c|}
\hline \multirow{3}{*}{ Variable } & \multicolumn{4}{|c|}{ Repeated suicide attempt within 6 months } & \multicolumn{4}{|c|}{ Repeated suicide attempt within 12 months } \\
\hline & \multicolumn{2}{|c|}{ Crude analysis } & \multicolumn{2}{|c|}{ Adjusted analysis } & \multicolumn{2}{|c|}{ Crude analysis } & \multicolumn{2}{|c|}{ Adjusted analysis } \\
\hline & $O R$ & $95 \% \mathrm{CI}$ & $O R$ & $95 \% \mathrm{CI}$ & $O R$ & $95 \% \mathrm{CI}$ & $O R$ & $95 \% \mathrm{CI}$ \\
\hline \multicolumn{9}{|l|}{$\operatorname{Sex}$} \\
\hline Female & 1 & & 1 & & 1 & & 1 & \\
\hline Male & 1.15 & $0.76-1.75$ & 1.37 & $0.84-2.23$ & 0.95 & $0.65-1.37$ & 1.00 & $0.65-1.56$ \\
\hline Age & 1.01 & $1.00-1.02$ & 1.00 & $0.98-1.02$ & 1.01 & $1.00-1.02$ & 1.00 & $0.98-1.02$ \\
\hline \multicolumn{9}{|l|}{ Suicide prevention team } \\
\hline No & 1 & & 1 & & 1 & & 1 & \\
\hline Yes & 1.21 & $0.81-1.80$ & 1.08 & $0.66-1.74$ & 1.07 & $0.76-1.51$ & 0.86 & $0.57-1.30$ \\
\hline \multicolumn{9}{|l|}{ Previous attempt } \\
\hline No & 1 & & 1 & & 1 & & 1 & \\
\hline One & 1.41 & $0.84-2.36$ & 1.41 & $0.80-2.48$ & 1.37 & $0.88-2.15$ & 1.30 & $0.79-2.11$ \\
\hline Several & $2.48^{*}$ & $1.38-4.44$ & $2.60 *$ & $1.38-4.87$ & $2.60^{*}$ & $1.56-4.33$ & $2.52 *$ & $1.45-4.41$ \\
\hline \multicolumn{9}{|l|}{ Aftercare referrals } \\
\hline Others & 1 & & 1 & & 1 & & 1 & \\
\hline Out-patient & $1.24 *$ & $1.02-1.52$ & 1.25 & $0.78-2.01$ & $1.59^{*}$ & $1.13-2.25$ & 1.15 & $0.94-1.42$ \\
\hline \multicolumn{9}{|l|}{ Alcohol misuse } \\
\hline No & 1 & & 1 & & 1 & & 1 & \\
\hline Yes & $1.66^{*}$ & $1.07-2.59$ & 1.02 & $0.58-1.79$ & $1.87 *$ & $1.28-2.73$ & 1.17 & $0.72-1.90$ \\
\hline \multicolumn{9}{|l|}{ Marital status } \\
\hline Others & 1 & & 1 & & 1 & & 1 & \\
\hline Married/cohabitant & 0.66 & $0.43-1.02$ & $0.56^{*}$ & $0.34-0.94$ & 0.74 & $0.51-1.07$ & $0.62 *$ & $0.40-0.96$ \\
\hline \multicolumn{9}{|l|}{ Employment } \\
\hline Employed & 1 & & 1 & & 1 & & 1 & \\
\hline Unemployed/disabled & 1.22 & $0.73-2.06$ & 0.96 & $0.54-1.72$ & 1.22 & $0.77-1.92$ & 1.00 & $0.60-1.66$ \\
\hline Student/pupil & $0.49^{*}$ & $0.24-0.99$ & $0.35^{*}$ & $0.15-0.81$ & $0.45^{*}$ & $0.24-0.84$ & $0.38 *$ & $0.18-0.79$ \\
\hline Others & 0.92 & $0.52-1.62$ & 1.05 & $0.53-2.11$ & 1.00 & $0.61-1.61$ & 1.07 & $0.59-1.93$ \\
\hline
\end{tabular}

* $P<0.05$ 
Table 4 - Cox regression analysis predicting repeated suicide attempt within $\mathbf{5}$ years after the index attempt.

\begin{tabular}{|c|c|c|c|c|}
\hline \multirow{2}{*}{ Variable } & \multicolumn{2}{|c|}{ Crude analysis } & \multicolumn{2}{|c|}{ Adjusted analysis } \\
\hline & $R R$ & $95 \% \mathrm{CI}$ & $R R$ & $95 \% \mathrm{CI}$ \\
\hline \multicolumn{5}{|l|}{$\operatorname{Sex}$} \\
\hline Female & 1 & & 1 & \\
\hline Male & 0.85 & $0.65-1.13$ & 0.81 & $0.59-1.13$ \\
\hline Age & 1.00 & 0.99.-1.01 & 1.00 & $0.99-1.01$ \\
\hline \multicolumn{5}{|l|}{ Suicide prevention team } \\
\hline No & 1 & & 1 & \\
\hline Yes & 1.16 & $0.90-1.50$ & 0.90 & $0.67-1.22$ \\
\hline \multicolumn{5}{|l|}{ Previous attempt } \\
\hline No & 1 & & 1 & \\
\hline One & 1.31 & $0.94-1.83$ & 1.16 & $0.81-1.67$ \\
\hline Several & $2.75^{*}$ & $1.94-3.91$ & $2.20^{*}$ & $1.50-3.24$ \\
\hline \multicolumn{5}{|l|}{ Aftercare referrals } \\
\hline Others & 1 & & 1 & \\
\hline Out-patient & $1.55^{*}$ & $1.20-2.00$ & 1.22 & $0.91-1.64$ \\
\hline \multicolumn{5}{|l|}{ Alcohol misuse } \\
\hline No & 1 & & 1 & \\
\hline Yes & $2.02 *$ & $1.55-2.64$ & $1.59 *$ & $1.14-2.22$ \\
\hline \multicolumn{5}{|l|}{ Marital status } \\
\hline Others & 1 & & 1 & \\
\hline Married/cohabitant & 0.79 & $0.60-1.03$ & 0.80 & $0.59-1.09$ \\
\hline \multicolumn{5}{|l|}{ Employment } \\
\hline Employed & 1 & & 1 & \\
\hline Unemployed/disabled & 1.29 & $0.94-1.78$ & 1.11 & $0.78-1.58$ \\
\hline Student/pupil & $0.46^{*}$ & $0.29-0.73$ & $0.47 *$ & $0.28-0.79$ \\
\hline Others & 0.73 & $0.50-1.08$ & 0.76 & $0.67-1.22$ \\
\hline
\end{tabular}

* $P<0.05$ 
Table 5 - Cox regression analysis of suicide mortality rates.

\begin{tabular}{|c|c|c|c|c|}
\hline \multirow{2}{*}{$\begin{array}{l}\text { Cox regression } \\
\text { Variable }\end{array}$} & \multicolumn{2}{|c|}{ Crude analysis } & \multicolumn{2}{|c|}{ Adjusted analysis } \\
\hline & $R R$ & $95 \% \mathrm{CI}$ & $R R$ & $95 \%$ CI \\
\hline \multicolumn{5}{|l|}{$\operatorname{Sex}$} \\
\hline Female & 1 & & 1 & \\
\hline Male & 1.48 & $0.80-2.74$ & 1.50 & $0.81-2.79$ \\
\hline Age & $1.03^{*}$ & $1.01-1.05$ & $1.03^{*}$ & $1.01-1.05$ \\
\hline \multicolumn{5}{|l|}{ Suicide prevention team } \\
\hline No & 1 & & 1 & \\
\hline Yes & 0.76 & $0.41-1.39$ & 0.85 & $0.46-1.57$ \\
\hline \multicolumn{5}{|l|}{ Previous attempt } \\
\hline No & 1 & & & \\
\hline One & 1.56 & $0.72-3.39$ & & \\
\hline Several & 0.93 & $0.47-3.95$ & & \\
\hline \multicolumn{5}{|l|}{ Aftercare referrals } \\
\hline Others & 1 & & 1 & \\
\hline Out-patient & 0.72 & $0.38-1.35$ & 0.88 & $0.64-1.21$ \\
\hline \multicolumn{5}{|l|}{ Alcohol misuse } \\
\hline No & 1 & & & \\
\hline Yes & 1.07 & $0.51-2.23$ & & \\
\hline \multicolumn{5}{|l|}{ Marital status } \\
\hline Others & 1 & & & \\
\hline Married/cohabitant & 1.28 & $0.67-2.48$ & & \\
\hline \multicolumn{5}{|l|}{ Employment } \\
\hline Employed & 1 & & & \\
\hline Unemployed/disabled & 1.48 & $0.57-3.81$ & & \\
\hline Student/pupil & 0.57 & $0.16-2.05$ & & \\
\hline Others & $2.82 *$ & $1.19-6.66$ & & \\
\hline
\end{tabular}

* $P<0.05$ 
